Supporting Information

\title{
Sequence-selective Recognition of Peptides within the Single Binding Pocket of a Self-Assembled Coordination Cage
}

Shohei Tashiro, Masahide Tominaga, Masaki Kawano, Bruno Therrien, Tomoji Ozeki, and Makoto Fujita*

\section{Contents}

- General procedure of peptide synthesis

- Physical data of $\mathbf{1} \cdot \mathbf{2}$

- NMR characterization of $\mathbf{1} \cdot \mathbf{2}$

$\left({ }^{1} \mathrm{H}\right.$ NMR, ${ }^{13} \mathrm{C}$ NMR, HOHAHA, NOESY, Argument about the solution structure of $\mathbf{1} \cdot \mathbf{2}$ by NOESY and chemical shift, HSQC, HMBC)

- Crystal data of $\mathbf{1} \cdot \mathbf{2}$

- ${ }^{1} \mathrm{H}$ NMR spectra of other peptides (3-9) in the cage 1

- Site-specific recognition of $\mathbf{1 0}$ and $\mathbf{1 1}$

- UV-visible titrations

\section{Peptide synthesis}

All peptides were synthesized by an automated peptide synthesizer (ABI 433A, Applied Biosystems) using the standard Fmoc-based FastMoc coupling chemistry (0.1 mmol scale). Peptides were cleaved from the resin with TFA $10 \mathrm{~mL}$ containing 5\% 
$(\mathrm{v} / \mathrm{v})$ water and $5 \%(\mathrm{v} / \mathrm{v})$ 1,2-ethanedithiol as a scavenger at room temperature for $3 \mathrm{~h}$. Free peptides were washed from the resin with $3 \mathrm{~mL}$ TFA followed by $5 \mathrm{~mL}$ dichloromethane and evaporated. To residues were added a large amount of $\mathrm{Et}_{2} \mathrm{O}$ and the precipitate was collected by filtration. Crude peptides were purified by reversedphase HPLC on an Inertsil ODS-3 semi-preparative column (10 mm x $250 \mathrm{~mm})$ using aqueous $0.1 \%$ TFA and acetonitrile gradient, and white powder of peptides was obtained by lyophilization.

\section{Physical data of $1 \cdot 2$}

${ }^{1} \mathrm{H}$ NMR (500 MHz, $\mathrm{D}_{2} \mathrm{O}, 27{ }^{\circ} \mathrm{C}$, TMS as external standard): $\square 9.67(\mathrm{~d}, J=5.0 \mathrm{~Hz}, 2 \mathrm{H}$, 1), $\square 9.63(\mathrm{~m}, 4 \mathrm{H}, \mathbf{1}), \square 9.54$ (d, $J=5.0 \mathrm{~Hz}, 1 \mathrm{H}, \mathbf{1}), \square 9.50$ (d, $J=4.5 \mathrm{~Hz}, 1 \mathrm{H}, \mathbf{1}), \square 9.42$ (m, 5H, 1), $\square 9.36$ (m, 2H, 1), $\square 9.31$ (m, 2H, 1), $\square 9.29$ (d, J = 5.7 Hz, 1H, 1), $\square 9.25$ (m, 4H, 1), $\square 9.21$ (d, J = 5.0 Hz, 1H, 1), $\square 9.15$ (m, 3H, 1), $\square 9.04$ (d, $J=5.0 \mathrm{~Hz}, 1 \mathrm{H}$, 1), $\square 9.01$ (d, $J=5.7 \mathrm{~Hz}, 1 \mathrm{H}, \mathbf{1}), \square 8.99$ (d, $J=5.0 \mathrm{~Hz}, 1 \mathrm{H}, \mathbf{1}), \square 8.84$ (m, 4H, 1), $\square 8.79$ $(\mathrm{d}, J=5.7 \mathrm{~Hz}, 1 \mathrm{H}, \mathbf{1}), \square 8.76(\mathrm{~d}, J=5.7 \mathrm{~Hz}, 1 \mathrm{H}, \mathbf{1}), \square 8.72(\mathrm{~m}, 3 \mathrm{H}, \mathbf{1}), \square 8.64$ (m, 3H, 1), $\square 8.52$ (d, $J=4.4 \mathrm{~Hz}, 1 \mathrm{H}, \mathbf{1}), \square 8.49$ (d, $J=4.4 \mathrm{~Hz}, 1 \mathrm{H}, \mathbf{1}), \square 8.45(\mathrm{~d}, J=4.4 \mathrm{~Hz}, 1 \mathrm{H}$, 1), $\square 8.35(\mathrm{~d}, J=4.4 \mathrm{~Hz}, 1 \mathrm{H}, \mathbf{1}), \square 8.22(\mathrm{~d}, J=4.4 \mathrm{~Hz}, 1 \mathrm{H}, \mathbf{1}), \square 8.12(\mathrm{~d}, J=4.4 \mathrm{~Hz}, 1 \mathrm{H}$, 1), $\square 5.99$ (s, 1H, 2), $\square 5.88$ (t, $J=6.9 \mathrm{~Hz}, 1 \mathrm{H}, 2), \square 5.70$ (d, $J=7.5 \mathrm{~Hz}, 1 \mathrm{H}, 2), \square 5.43$ $(\mathrm{t}, J=6.9 \mathrm{~Hz}, 1 \mathrm{H}, 2), \square 5.37(\mathrm{t}, J=6.9 \mathrm{~Hz}, 1 \mathrm{H}, 2), \square 4.85(\mathrm{~d}, J=7.5 \mathrm{~Hz}, 1 \mathrm{H}, 2), \square 4.63$ $(\mathrm{d}, J=7.0 \mathrm{~Hz}, 1 \mathrm{H}, 2), \square 4.35(\mathrm{t}, J=6.9 \mathrm{~Hz}, 1 \mathrm{H}, 2), \square 3.99$ (t, $J=8.8 \mathrm{~Hz}, 1 \mathrm{H}, 2), \square 3.67$ (d, $J=7.0 \mathrm{~Hz}, 1 \mathrm{H}, 2), \square 3.17$ (m, 24H, 1), $\square 2.73$ (m, 72H, 1), $\square 2.54$ (s, 3H, 2), $\square 2.45$ (s, 1H, 2), $\square 1.29$ (d, $J=6.0 \mathrm{~Hz}, 2 \mathrm{H}, 2), \square 0.99$ (d, $J=8.0 \mathrm{~Hz}, 1 \mathrm{H}, 2), \square-0.86$ (t, $J=$ $12.8 \mathrm{~Hz}, 1 \mathrm{H}, 2), \square-1.89(\mathrm{~d}, J=5.5 \mathrm{~Hz}, 3 \mathrm{H}, 2) .{ }^{13} \mathrm{C} \mathrm{NMR}\left(125 \mathrm{MHz}, \mathrm{D}_{2} \mathrm{O}, 27{ }^{\circ} \mathrm{C}\right.$, TMS as external standard): $\square 174.2(C O, 2), \square 173.0(C O, 2), \square 172.6(C O, 2), \square$ 169.4-168.0 (Cq, 1), $\square 166.7$ (CO, 2), $\square 153.2-151.7$ (CH, 1), $\square 146.9-144.8$ (Cq, 1), $\square$ 134.6 (Cq, 2), $\square 133.9$ (Cq, 2), $\square 126.8-125.8$ (CH, 1), $\square 124.8$ (Cq, 2), $\square 124.6$ (CH, 2), $\square 123.9$ (Cq, 2), $\square 122.1$ (CH, 2), $\square 121.5$ (CH, 2), $\square 120.9$ (CH, 2), $\square 119.7(C H, 2), \square$ 118.9 (CH, 2), $\square 117.8$ (CH, 2), $\square 116.6(\mathrm{CH}, 2), \square 109.9(\mathrm{CH}, 2), \square 109.1(\mathrm{CH}, 2), \square$ 108.6 (Cq, 2), $\square 107.6$ (Cq, 2), $\square 62.9\left(\mathrm{CH}_{2}, \mathbf{1}\right), \square 56.2(\mathrm{CH}, 2), \square 50.5\left(\mathrm{CH}_{3}, \mathbf{1}\right), \square 47.2$ $(\mathrm{CH}, 2), \square 28.7\left(\mathrm{CH}_{2}, 2\right), \square 27.1\left(\mathrm{CH}_{2}, \mathbf{2}\right), \square 22.2\left(\mathrm{CH}_{3}, 2\right), \square 13.9\left(\mathrm{CH}_{3}, \mathbf{2}\right) . \quad \mathrm{IR}(\mathrm{KBr}$, $\left.\mathrm{cm}^{-1}\right)$ : 3412 (br), 3098, 3017, 2988, 2923, 1664, 1655, 1573, 1522, 1381, 1060, 810. Mp.: 212-228 ${ }^{\circ} \mathrm{C}$ (dec.). Elemental analysis calcd. for $\mathrm{C}_{135} \mathrm{H}_{174} \mathrm{~N}_{54} \mathrm{O}_{40} \mathrm{Pd}_{6} \cdot 34 \mathrm{H}_{2} \mathrm{O}: \mathrm{C}$, 36.48; H, 5.49; N, 17.02. Found: C, 36.36; H, 5.14; N, 16.73 . 
NMR characterization of $1 \cdot 2$

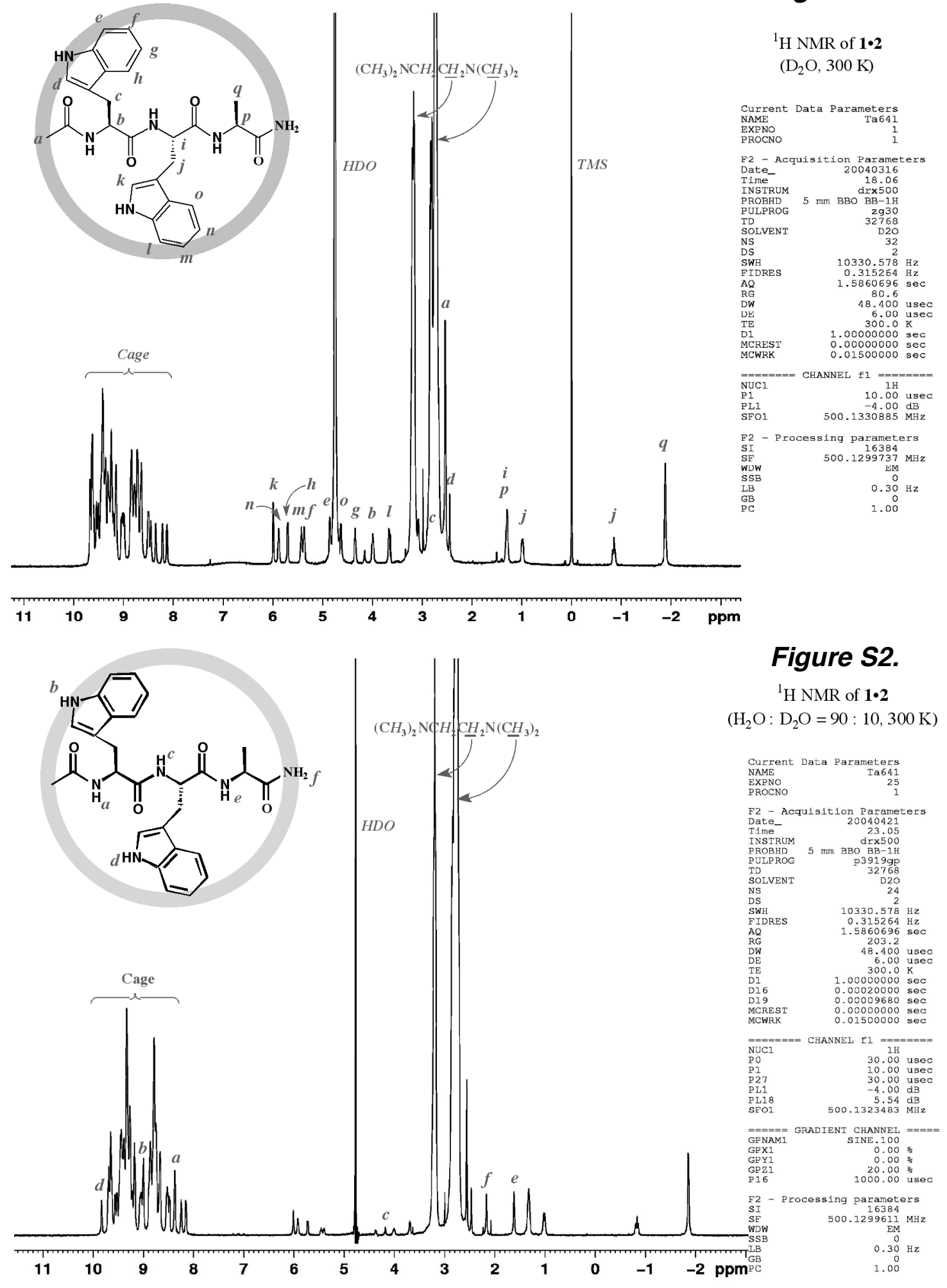

Figure S1.

${ }^{1} \mathrm{H}$ NMR of $\mathbf{1} \bullet$

rrent Data Paramete

PROCNO

$\begin{array}{cc}20040316 \\ \text { Date- } & 18.06\end{array}$

5 III BBO $\begin{gathered}\text { drx } \\ \mathrm{BB}-1\end{gathered}$

LVEN

-578
.315264

18.400 usec
6.00 use

ters

0 


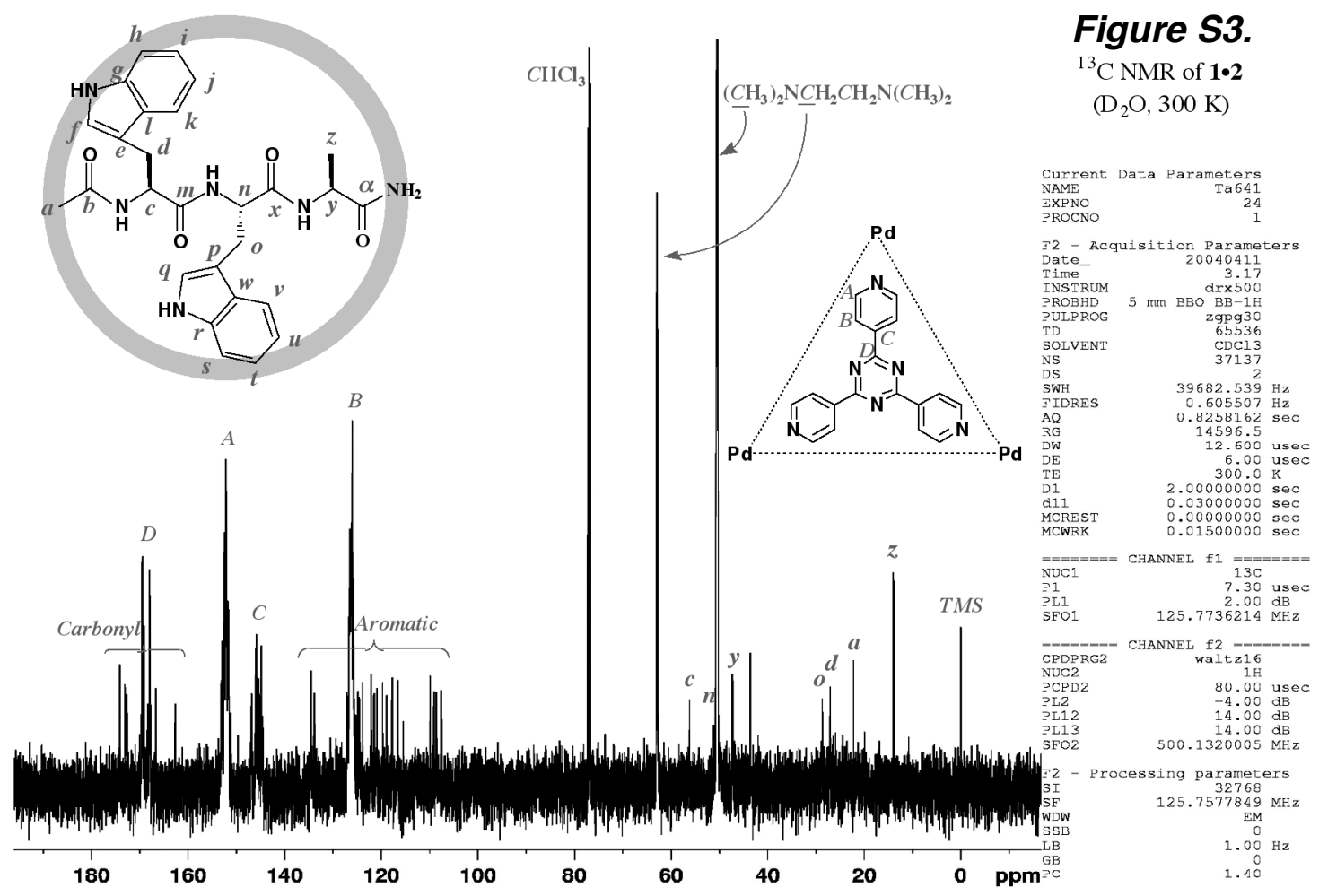

Figure S4.
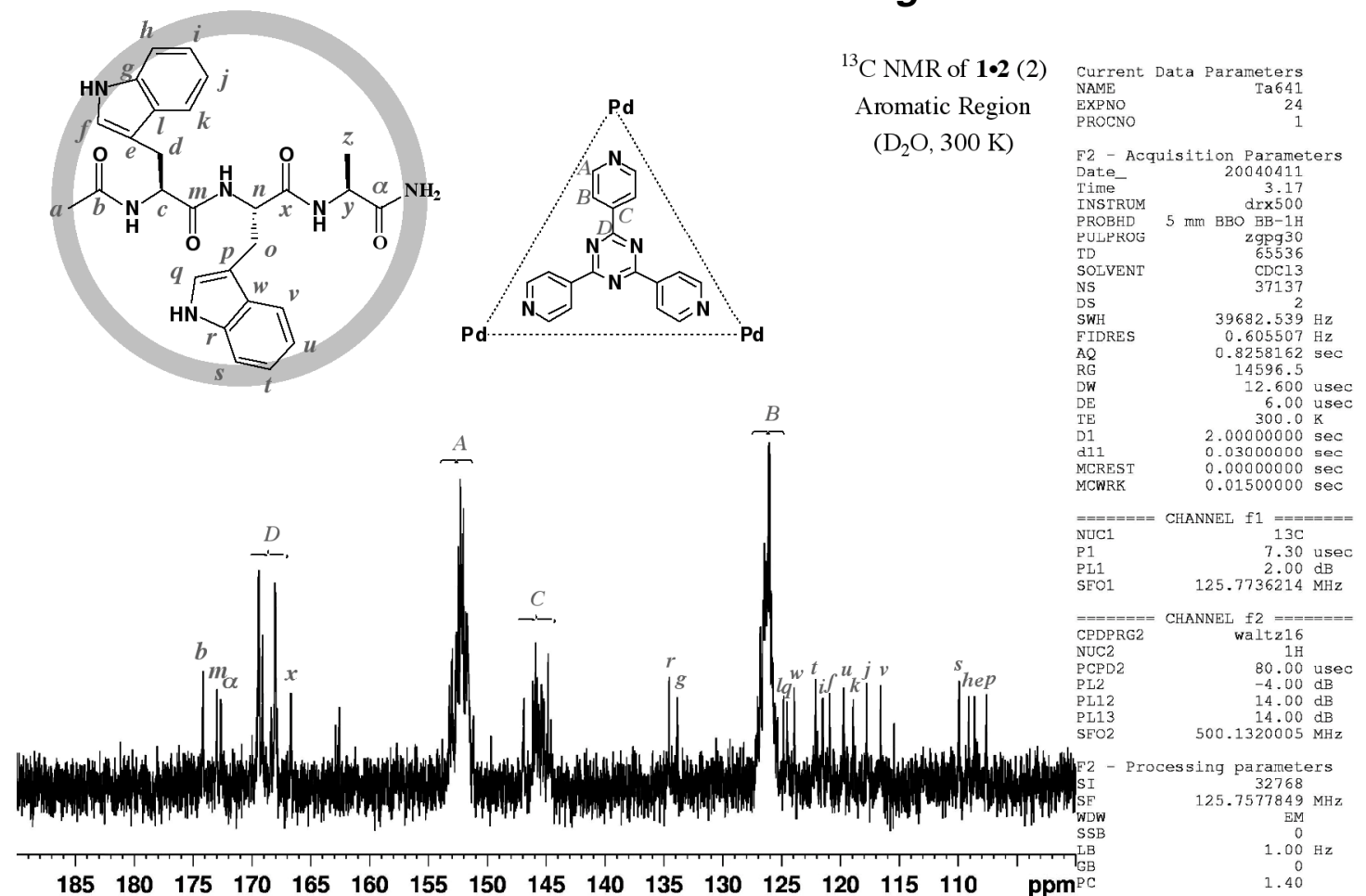


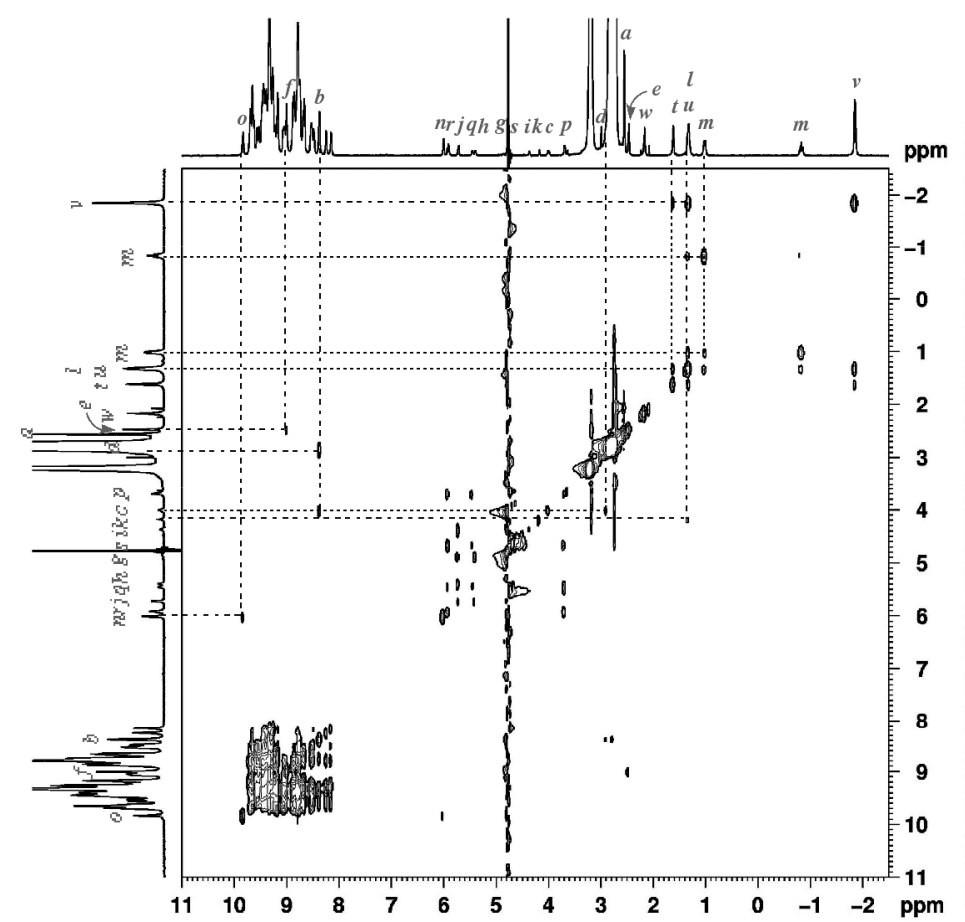

Figure S5.

IOHAIIA of $\mathbf{1 \cdot 2}$
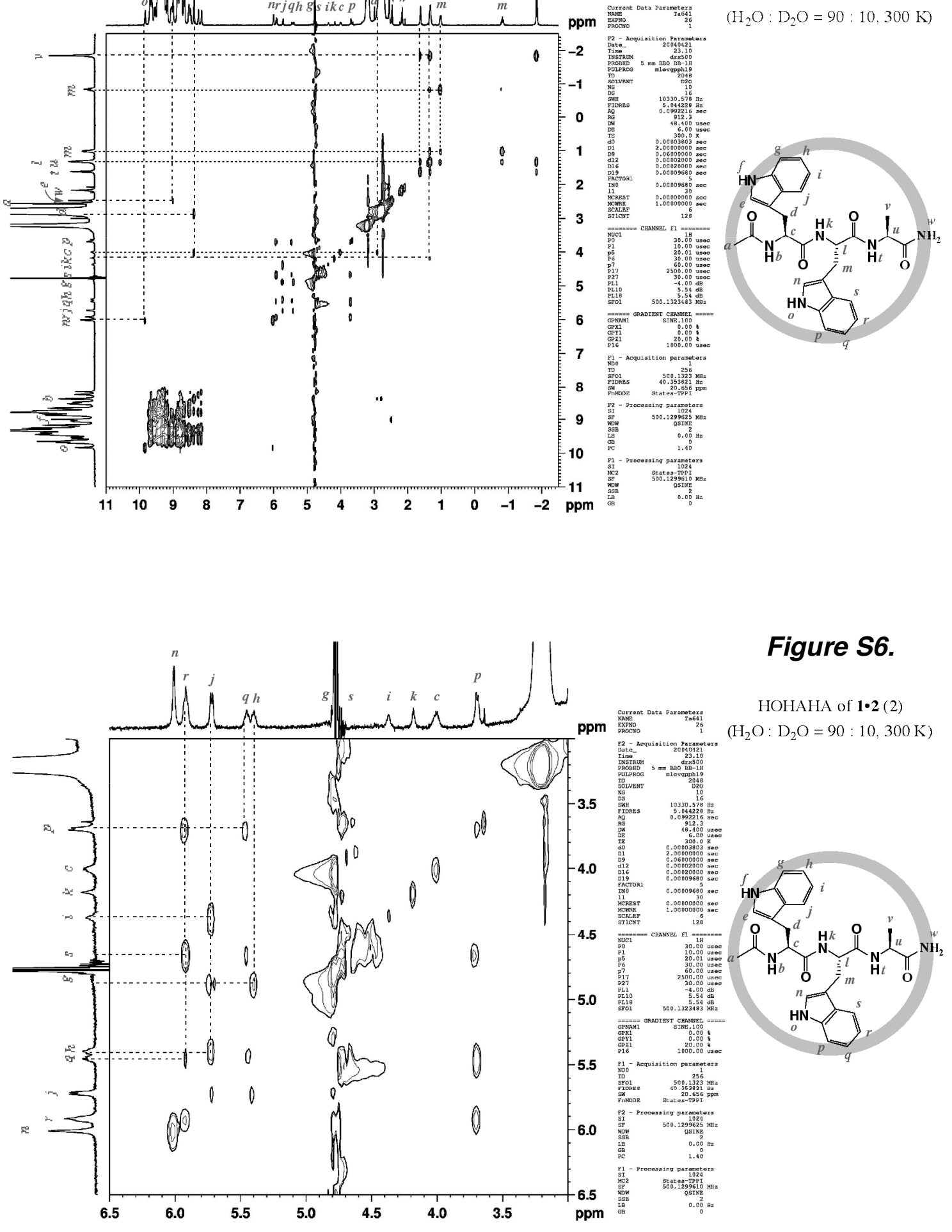


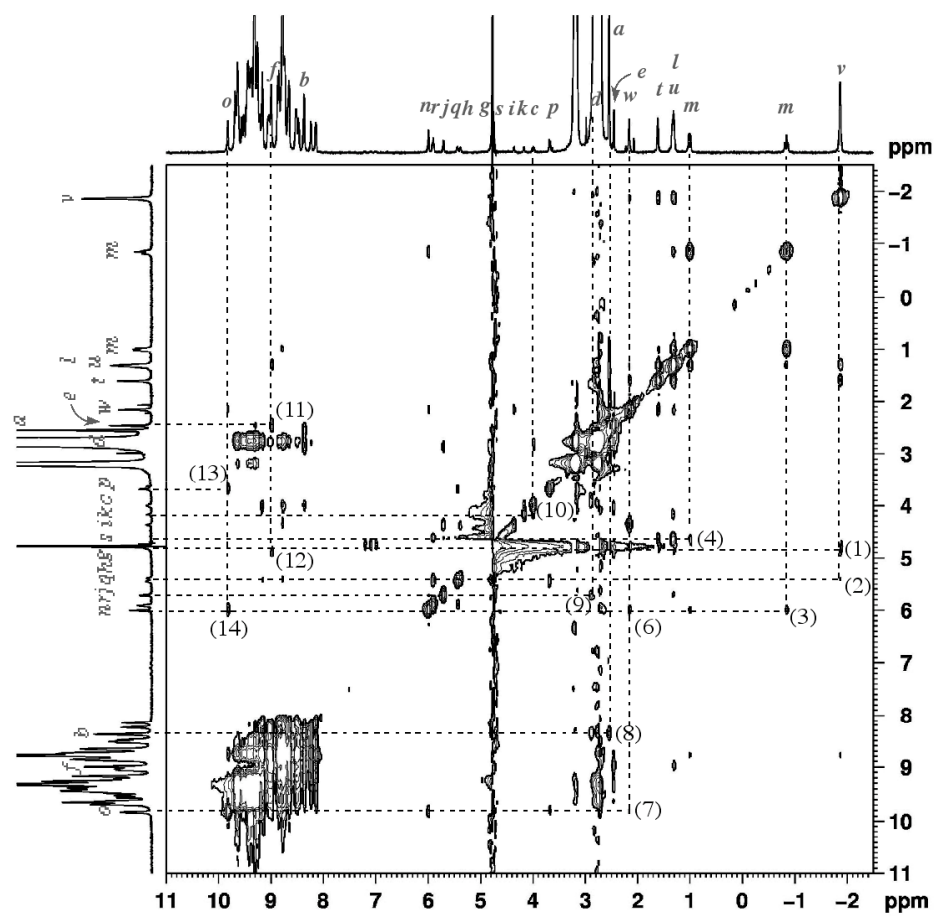

Figure S7.

YOESY of $\mathbf{1} \cdot \mathbf{2}$

$\left(\mathrm{H}_{2} \mathrm{O}: \mathrm{D}_{2} \mathrm{O}=90: 10.300 \mathrm{~K}\right)$

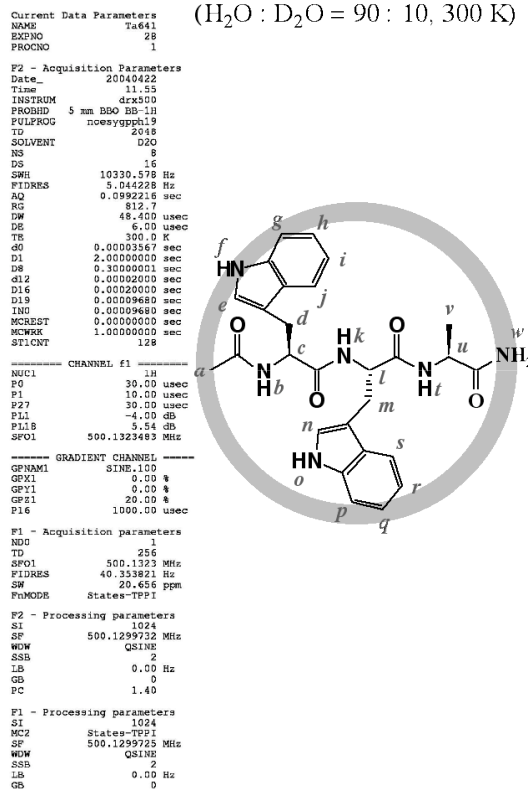

Figure S8.

NOE peaks of $\mathbf{1} \cdot \mathbf{2}$

$\left(\mathrm{H}_{2} \mathrm{O}: \mathrm{D}_{2} \mathrm{O}=90: 10,300 \mathrm{~K}\right)$

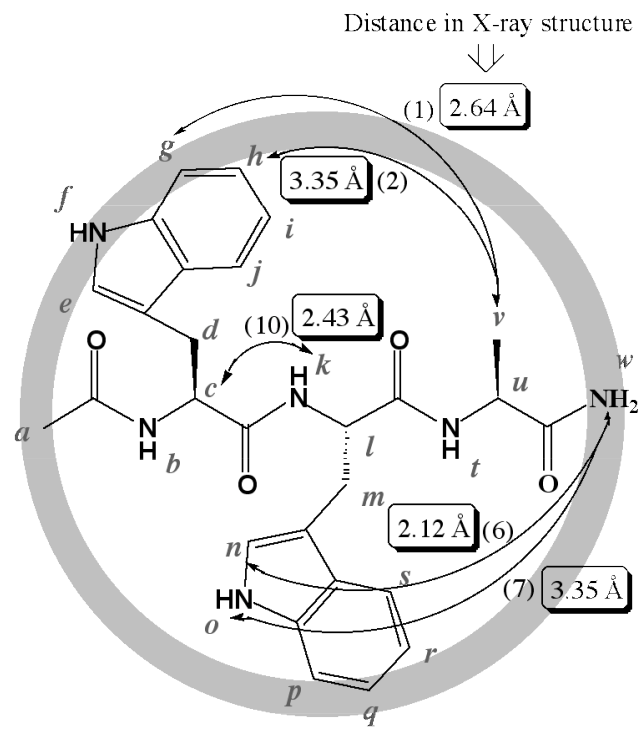

Intra-residue cross peaks

Inter-residue cross peaks 


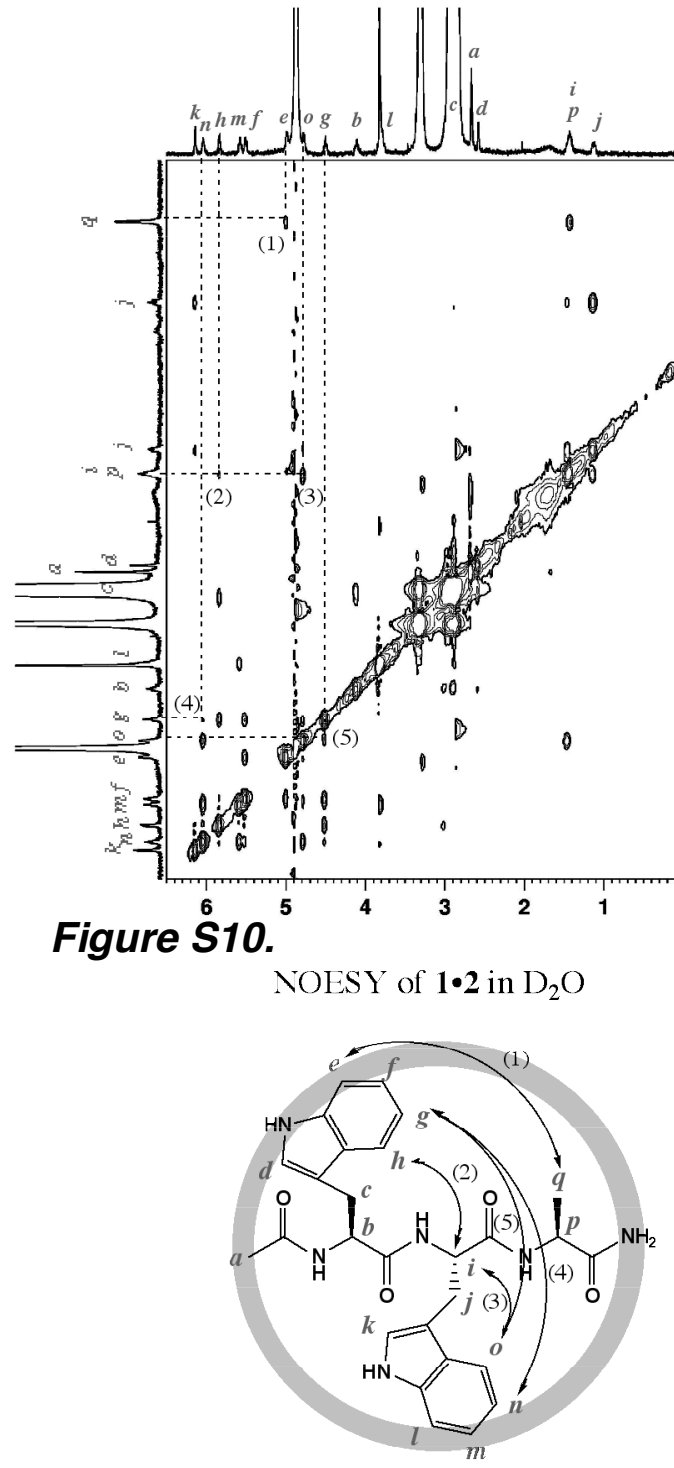

Figure S9.

TOESY of $\mathbf{1 \cdot 2}$

$\left(D_{2} \mathrm{O} .300 \mathrm{~K}\right.$ )

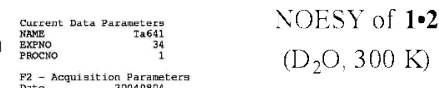

Figure S11.

Chemical shift comparison of free WWA and WWA in $\mathbf{1}$

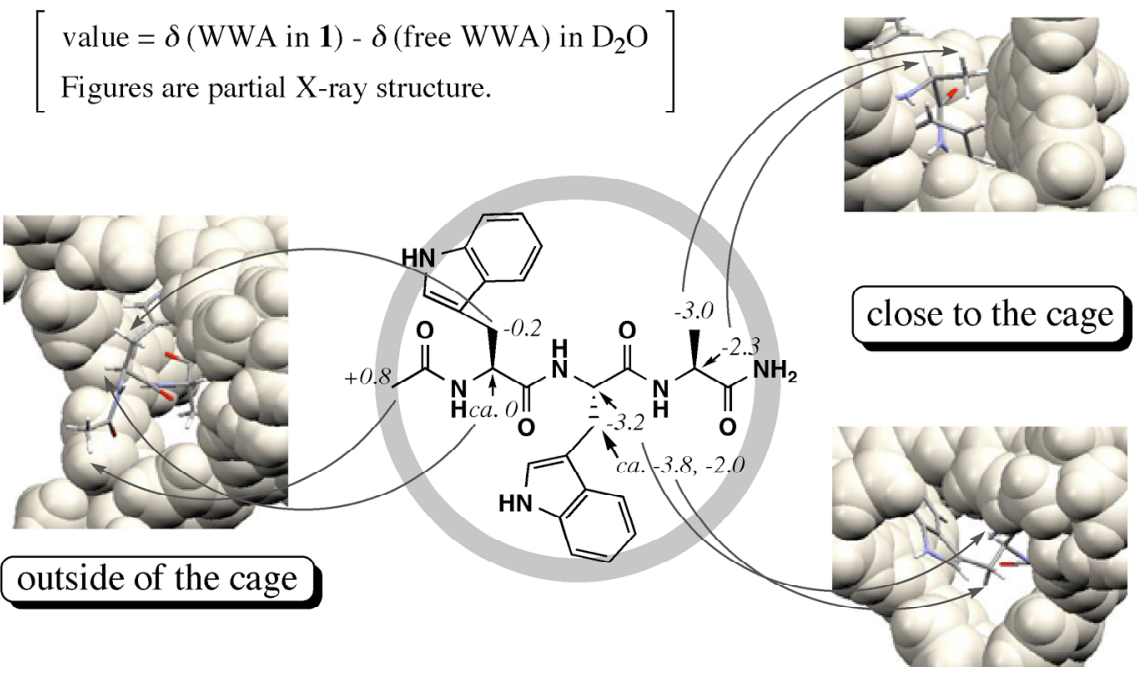


Figure S12.

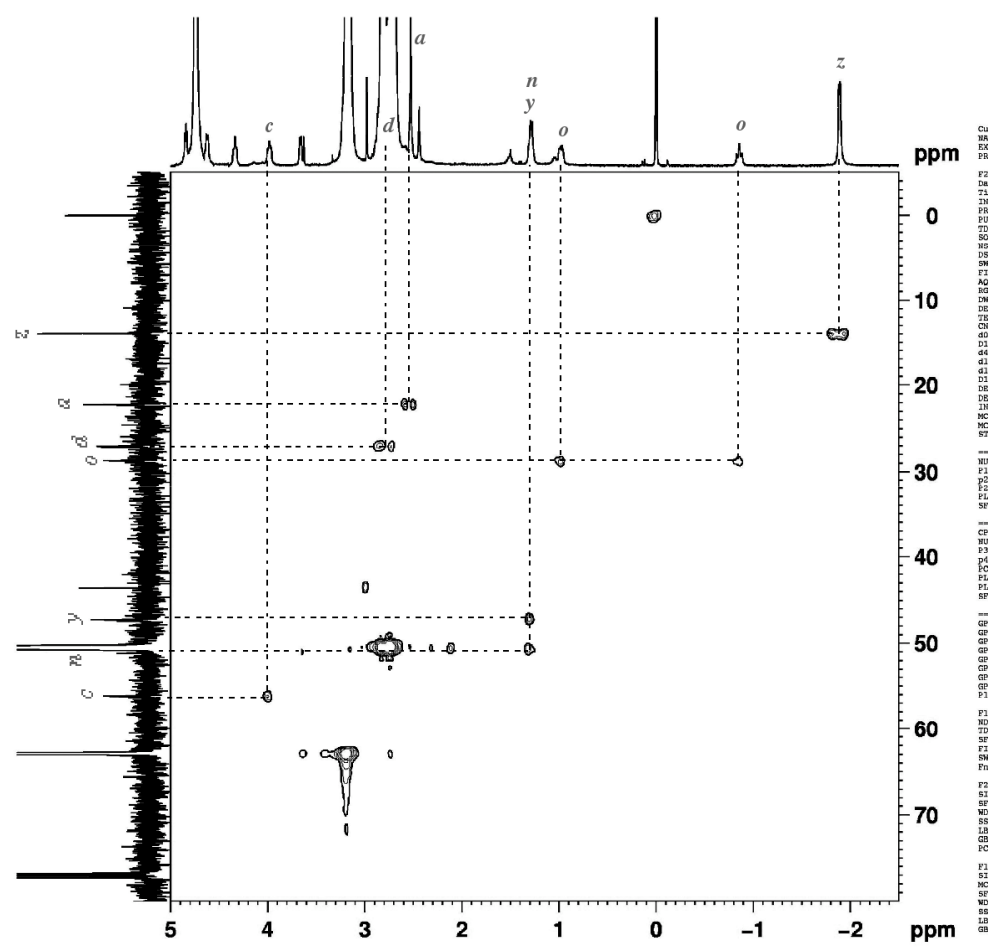

HSQC of $\mathbf{1 \cdot 2}$

Aliphatic Region

$\left(\mathrm{D}_{2} \mathrm{O}, 300 \mathrm{~K}\right)$

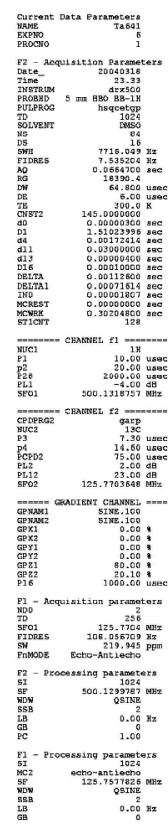

Figure S13.

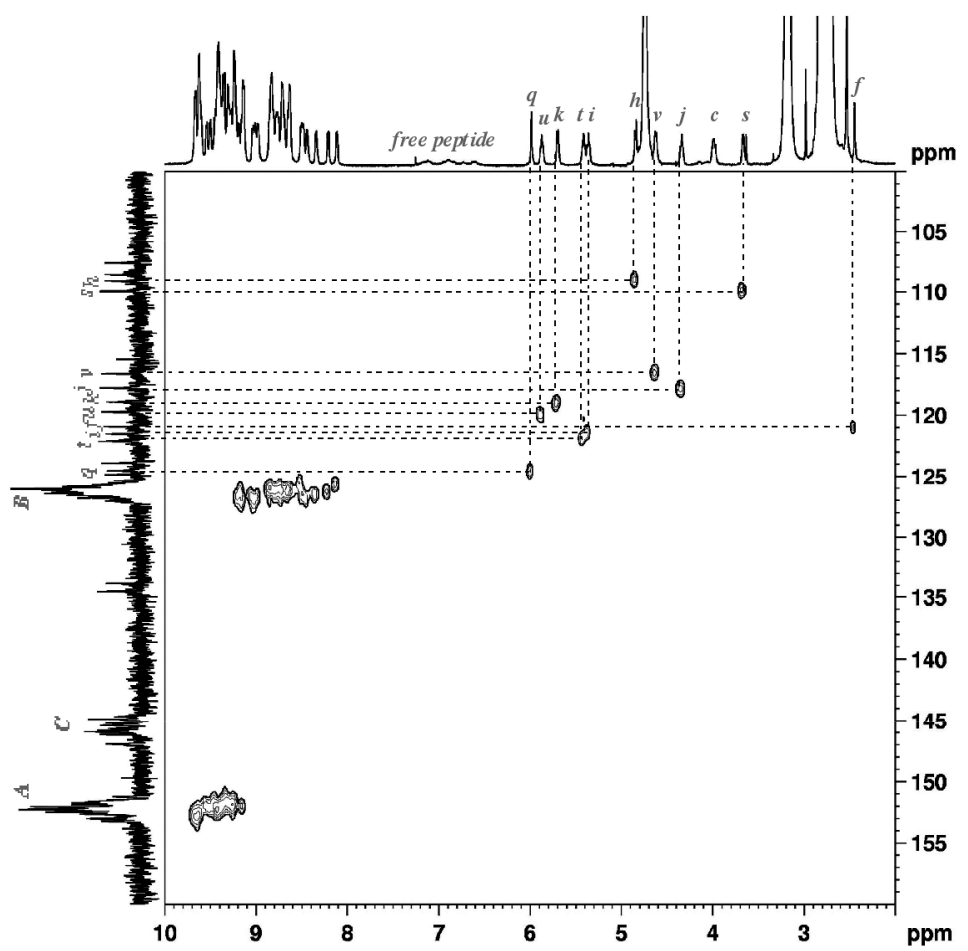

HSQC of $\mathbf{1 \cdot 2}$ (2)

Aromatic Region

$\left(D_{2} \mathrm{O}, 300 \mathrm{~K}\right)$

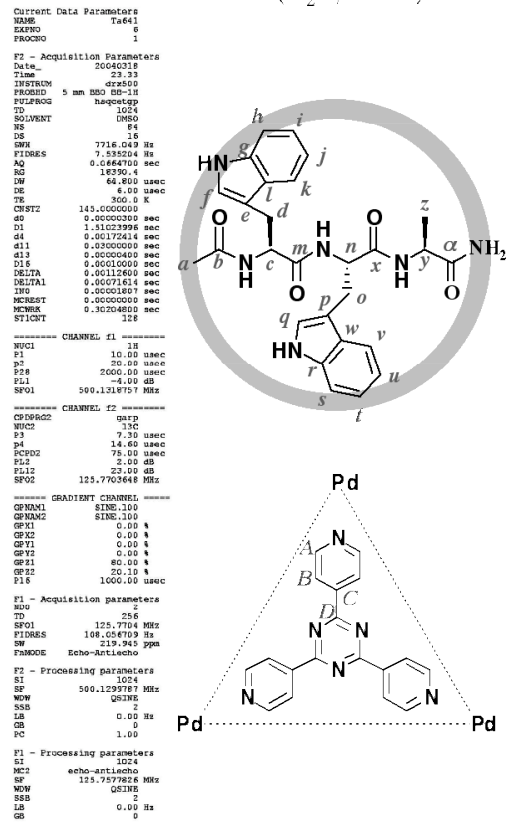


Figure S14.

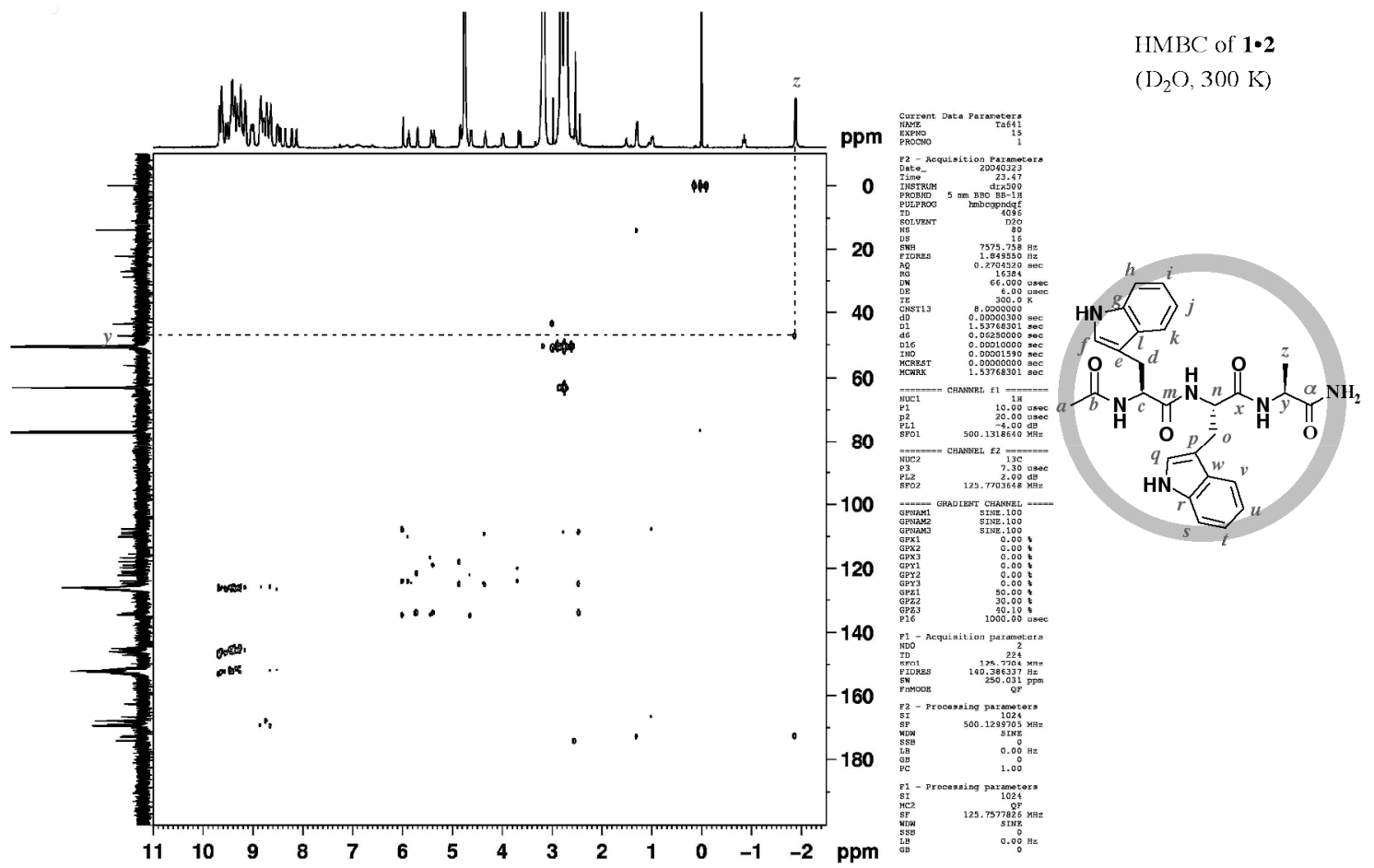

Figure S15.

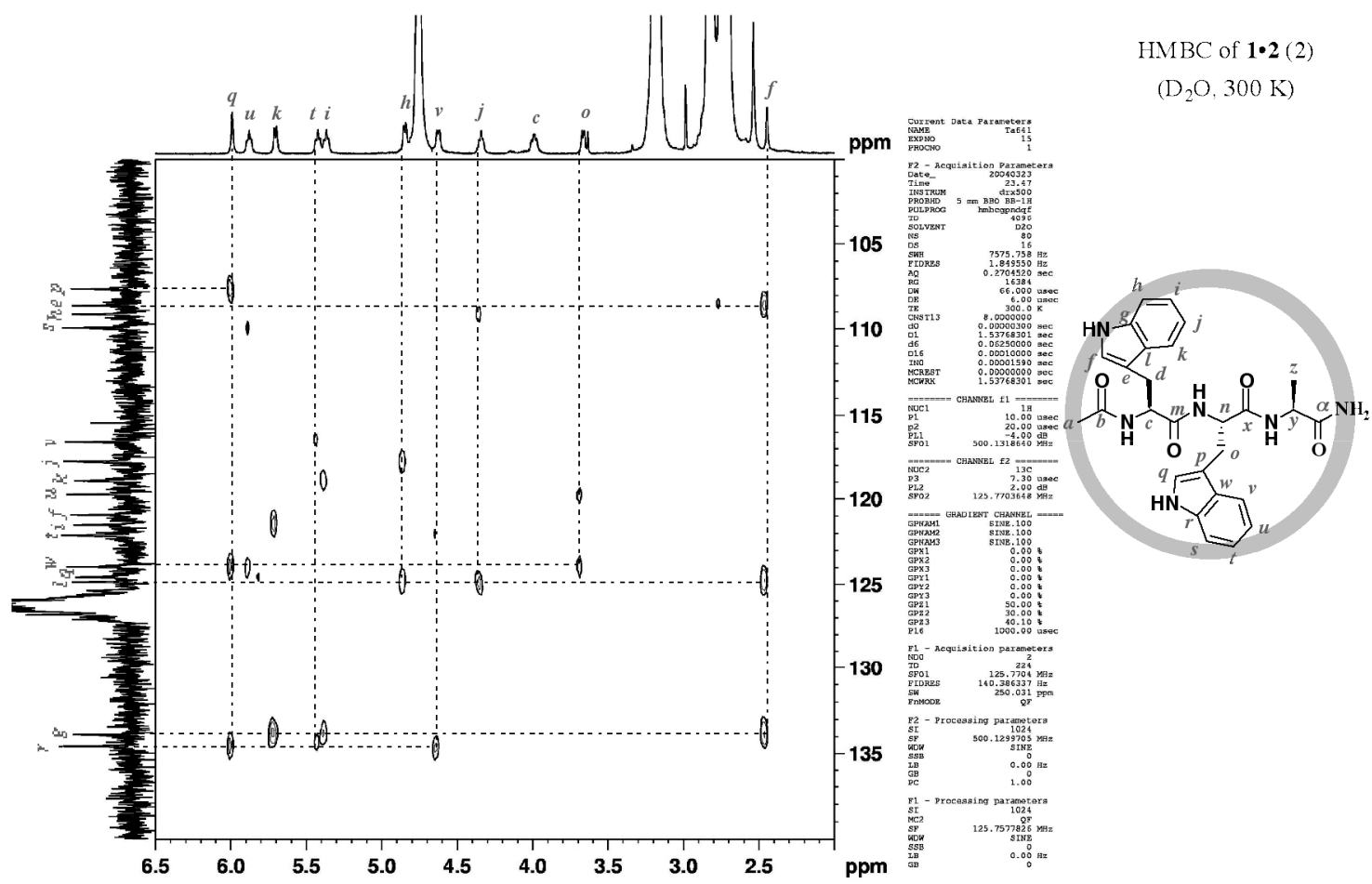


Figure S16.

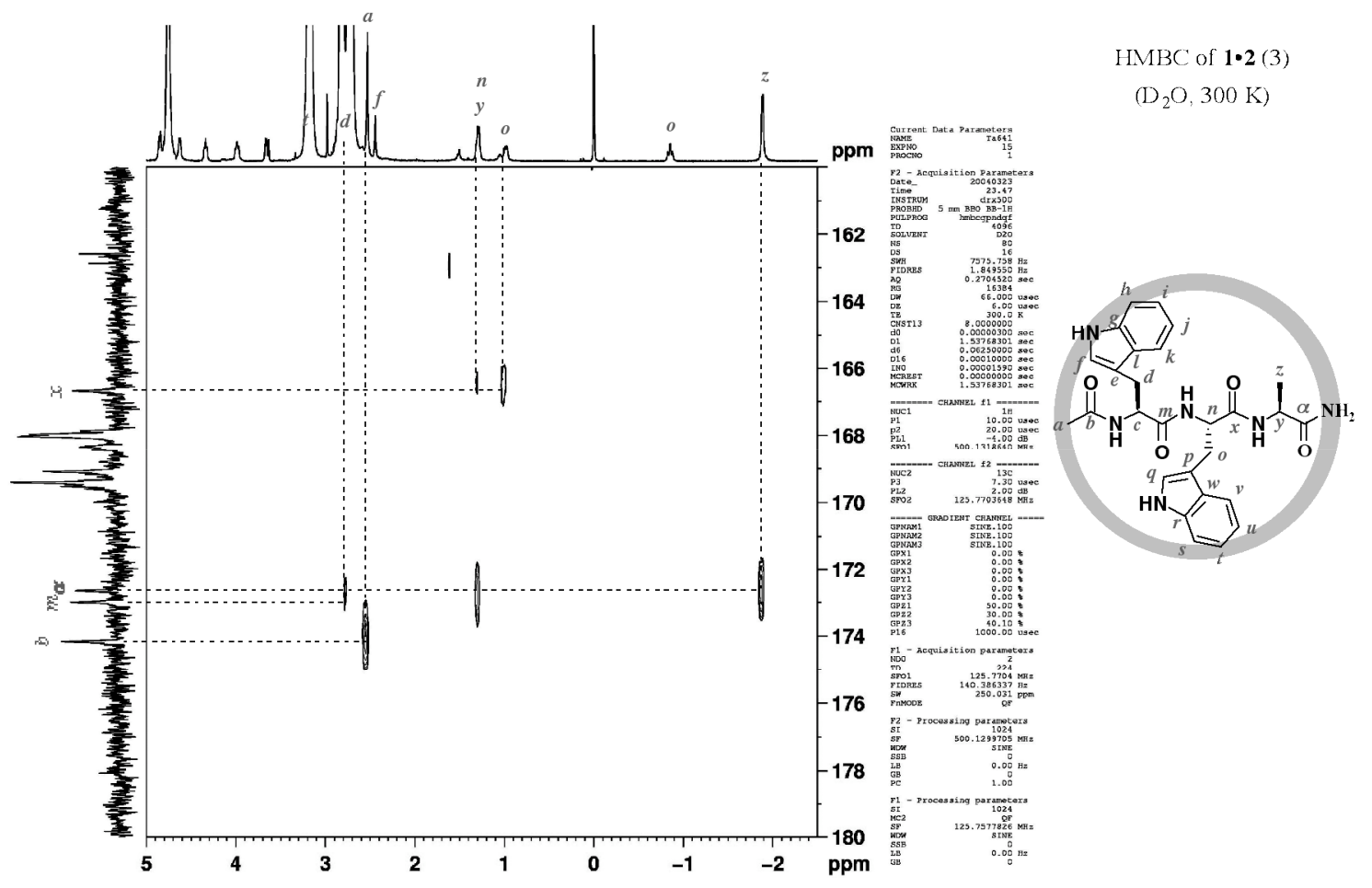




\section{Crystal data of $\mathbf{1} \mathbf{2}$}

Table S1. Crystal data of $\mathbf{1} \mathbf{2}$.

\begin{tabular}{|c|c|c|}
\hline Empirical formula & \multicolumn{2}{|c|}{ C135 H202 N54 O54 Pd6 } \\
\hline Formula weight & \multicolumn{2}{|l|}{4083.90} \\
\hline Temperature & \multicolumn{2}{|l|}{$15(2) \mathrm{K}$} \\
\hline Wavelength & \multicolumn{2}{|l|}{$0.6890 \AA$} \\
\hline Crystal system & \multicolumn{2}{|l|}{ Monoclinic } \\
\hline Space group & \multicolumn{2}{|l|}{$C 2 / \mathrm{c}$} \\
\hline \multirow[t]{3}{*}{ Unit cell dimensions } & $a=70.377(14) \AA$ & $\square=90.00^{\circ}$ \\
\hline & $\mathrm{b}=17.181(3) \AA$ & $\square=99.90^{\circ}$ \\
\hline & $c=42.159(8) \AA$ & $\square=90.00^{\circ}$ \\
\hline Volume & \multicolumn{2}{|l|}{$50217(17) \AA^{3}$} \\
\hline $\mathrm{Z}$ & \multicolumn{2}{|l|}{8} \\
\hline Density (calculated) & \multicolumn{2}{|l|}{$1.068 \mathrm{~g} / \mathrm{cm}^{3}$} \\
\hline Absorption coefficient & \multicolumn{2}{|l|}{$0.447 \mathrm{~mm}^{-1}$} \\
\hline $\mathrm{F}(000)$ & \multicolumn{2}{|c|}{16481} \\
\hline Crystal size & \multicolumn{2}{|c|}{$0.26 \times 0.12 \times 0.09 \mathrm{~mm}^{3}$} \\
\hline Theta range for data collection & \multicolumn{2}{|c|}{1.76 to $26.37^{\circ}$} \\
\hline Index ranges & \multicolumn{2}{|c|}{$-87<=\mathrm{h}<=86,-20<=\mathrm{k}<=19,-52<=1<=52$} \\
\hline Reflections collected & \multicolumn{2}{|l|}{142086} \\
\hline Independent reflections & \multicolumn{2}{|c|}{$47250[\mathrm{R}(\mathrm{int})=0.0714]$} \\
\hline Completeness to theta $=26.37^{\circ}$ & \multicolumn{2}{|l|}{$92.0 \%$} \\
\hline Absorption correction & \multicolumn{2}{|l|}{ none } \\
\hline Refinement method & \multicolumn{2}{|c|}{ Full-matrix least-squares on $\mathrm{F}^{2}$} \\
\hline Data / restraints / parameters & \multicolumn{2}{|c|}{$47250 / 1625 / 2114$} \\
\hline Goodness-of-fit on $\mathrm{F}^{2}$ & \multicolumn{2}{|c|}{1.378} \\
\hline Final $R$ indices [I>2sigma(I)] & \multicolumn{2}{|c|}{$\mathrm{R} 1=0.1518, \mathrm{wR} 2=0.4191$} \\
\hline $\mathrm{R}$ indices (all data) & \multicolumn{2}{|c|}{$\mathrm{R} 1=0.2242, \mathrm{wR} 2=0.4521$} \\
\hline Largest diff. peak and hole & \multicolumn{2}{|c|}{1.532 and $-1.824 \mathrm{e}^{-3}$} \\
\hline
\end{tabular}


${ }^{1} \mathrm{H}$ NMR of 1 with peptide 3-9
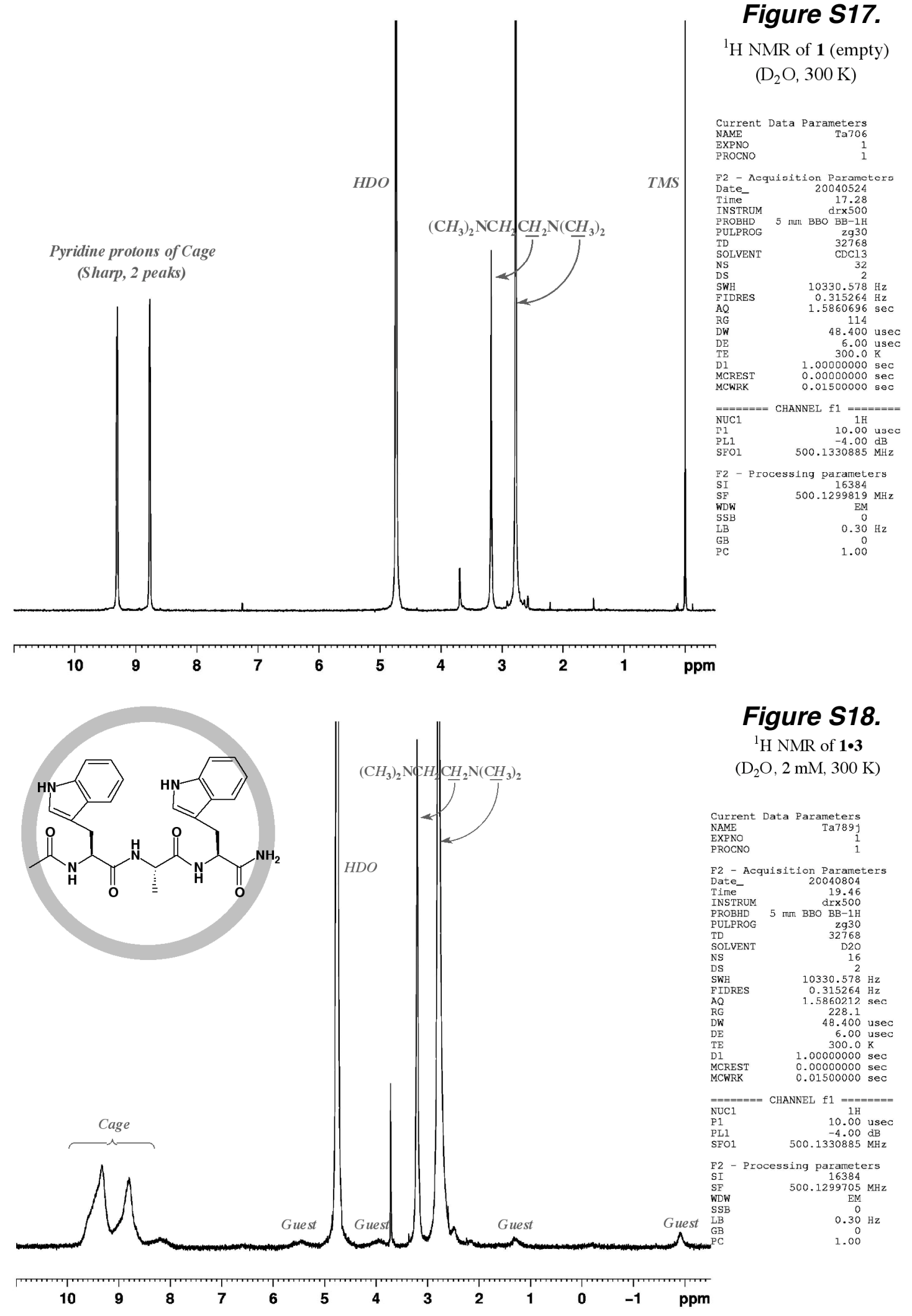


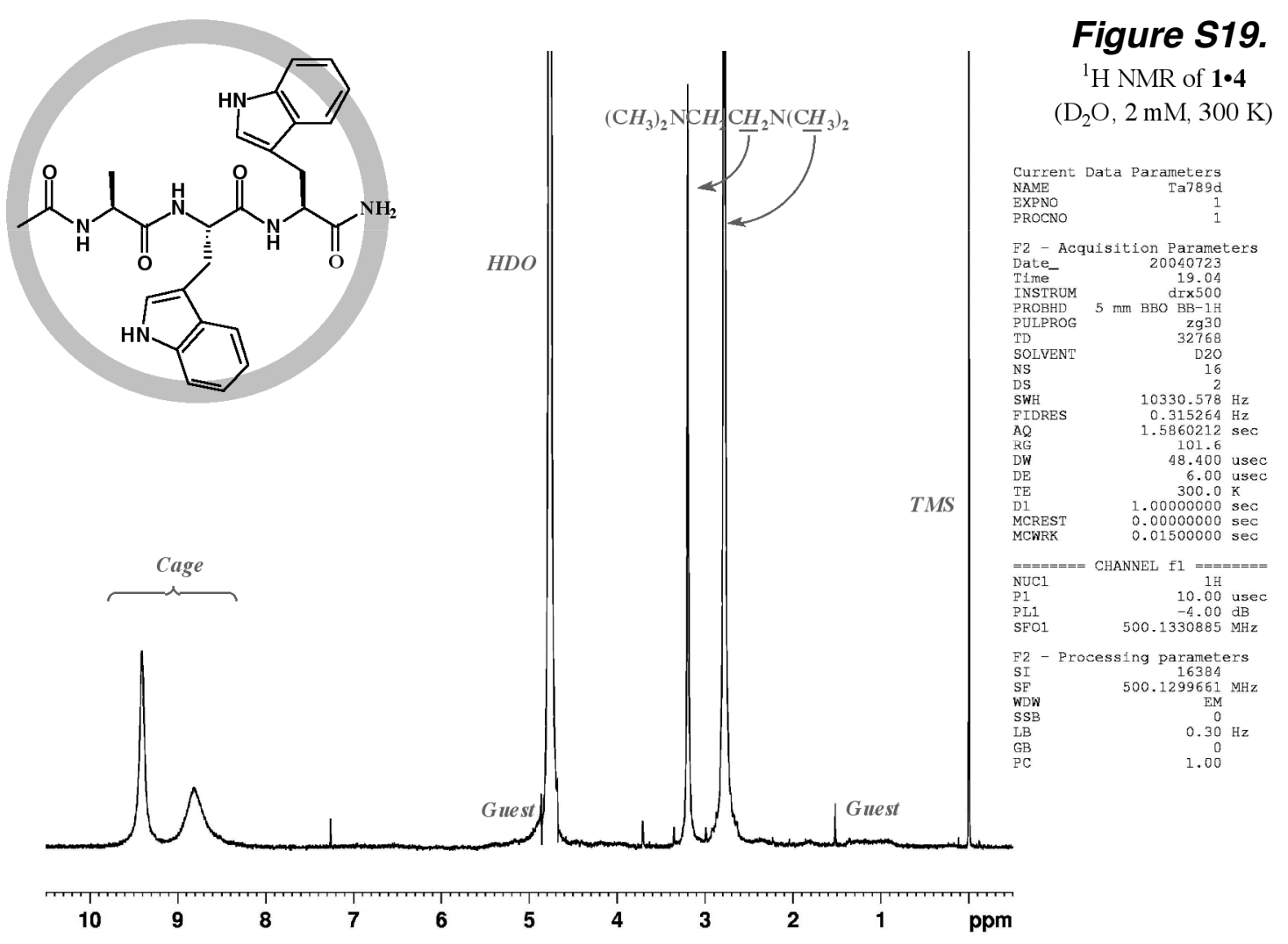

Figure S20.

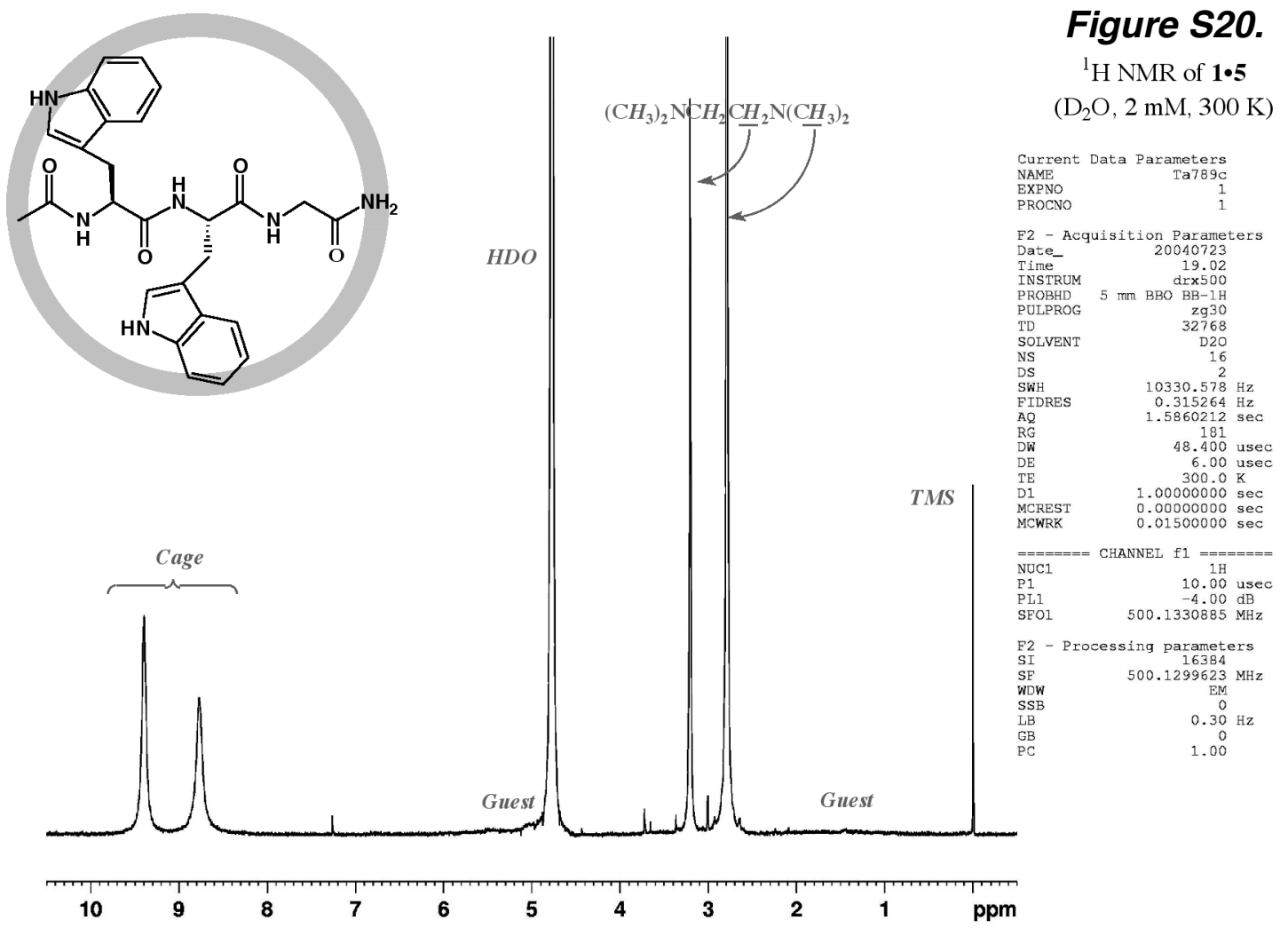



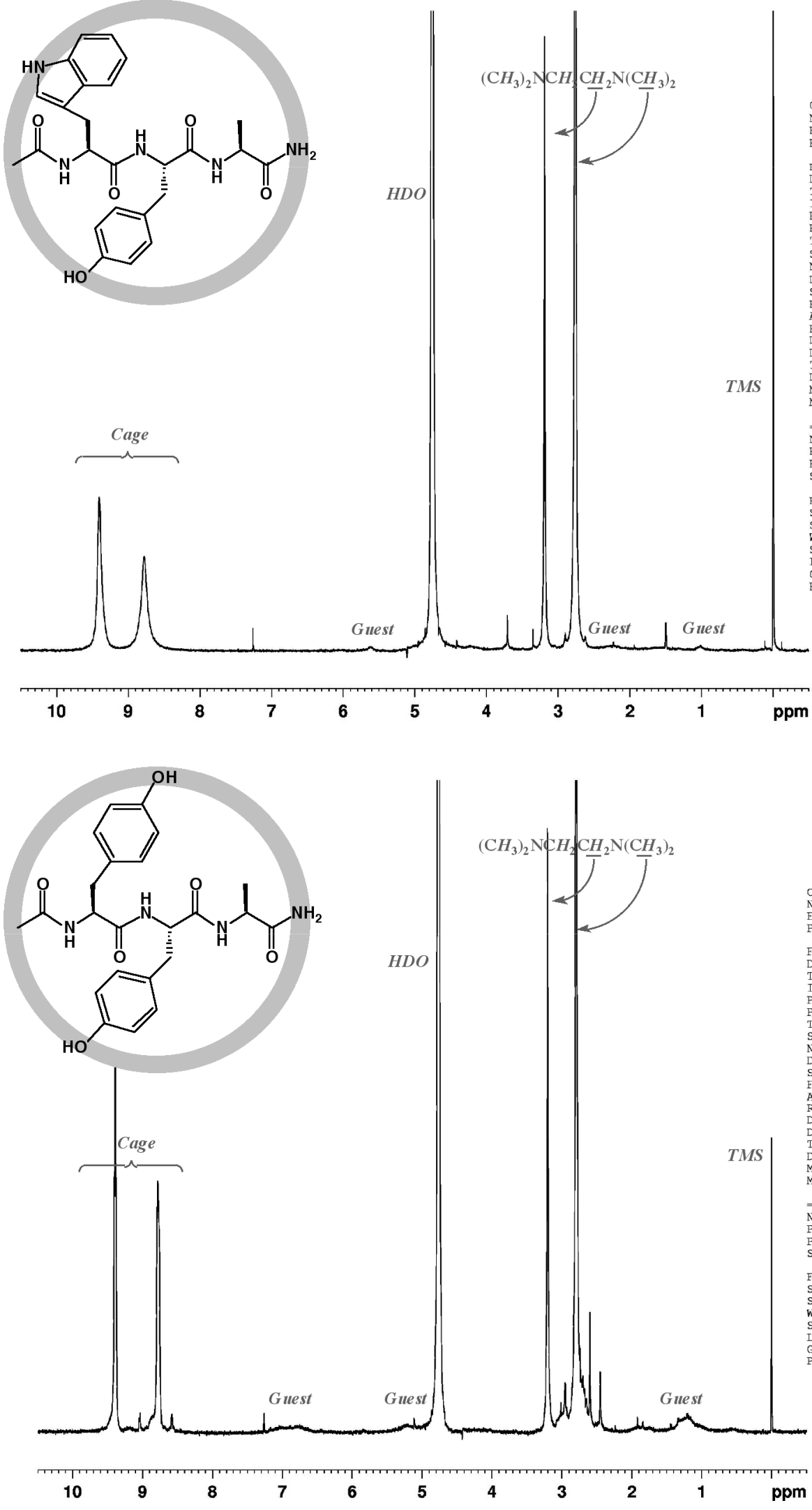


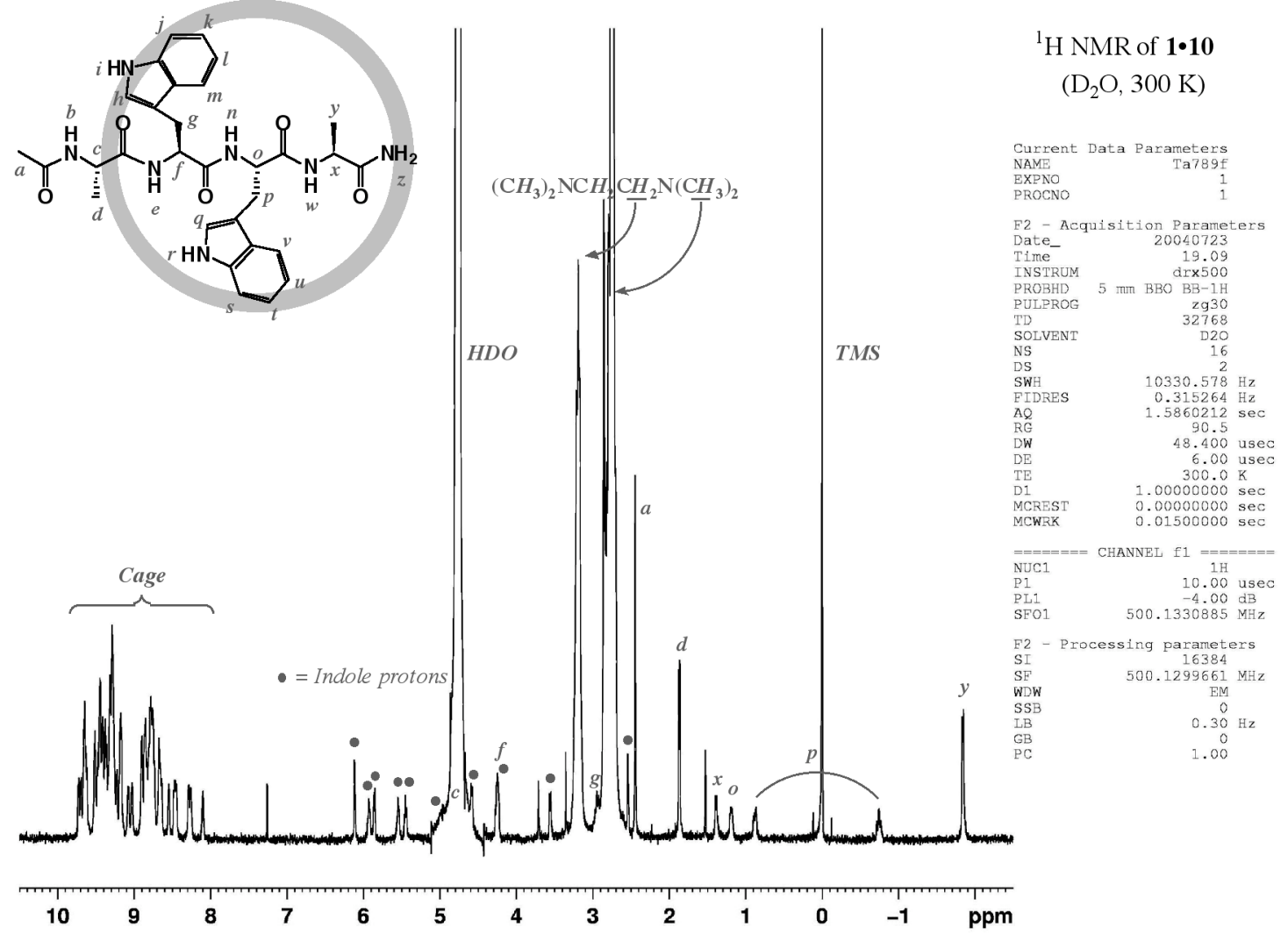

Figure S24.

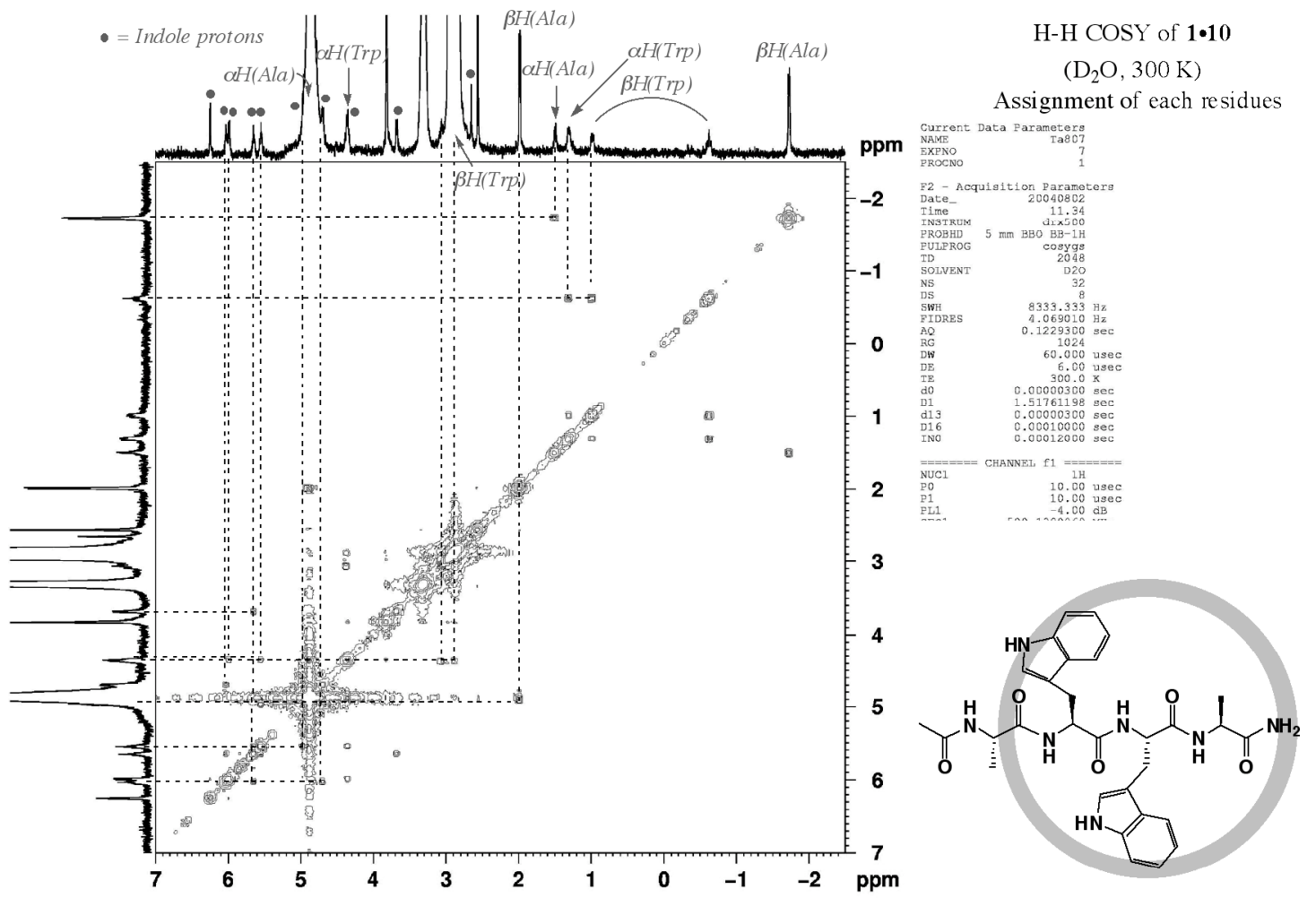


Figure S25.
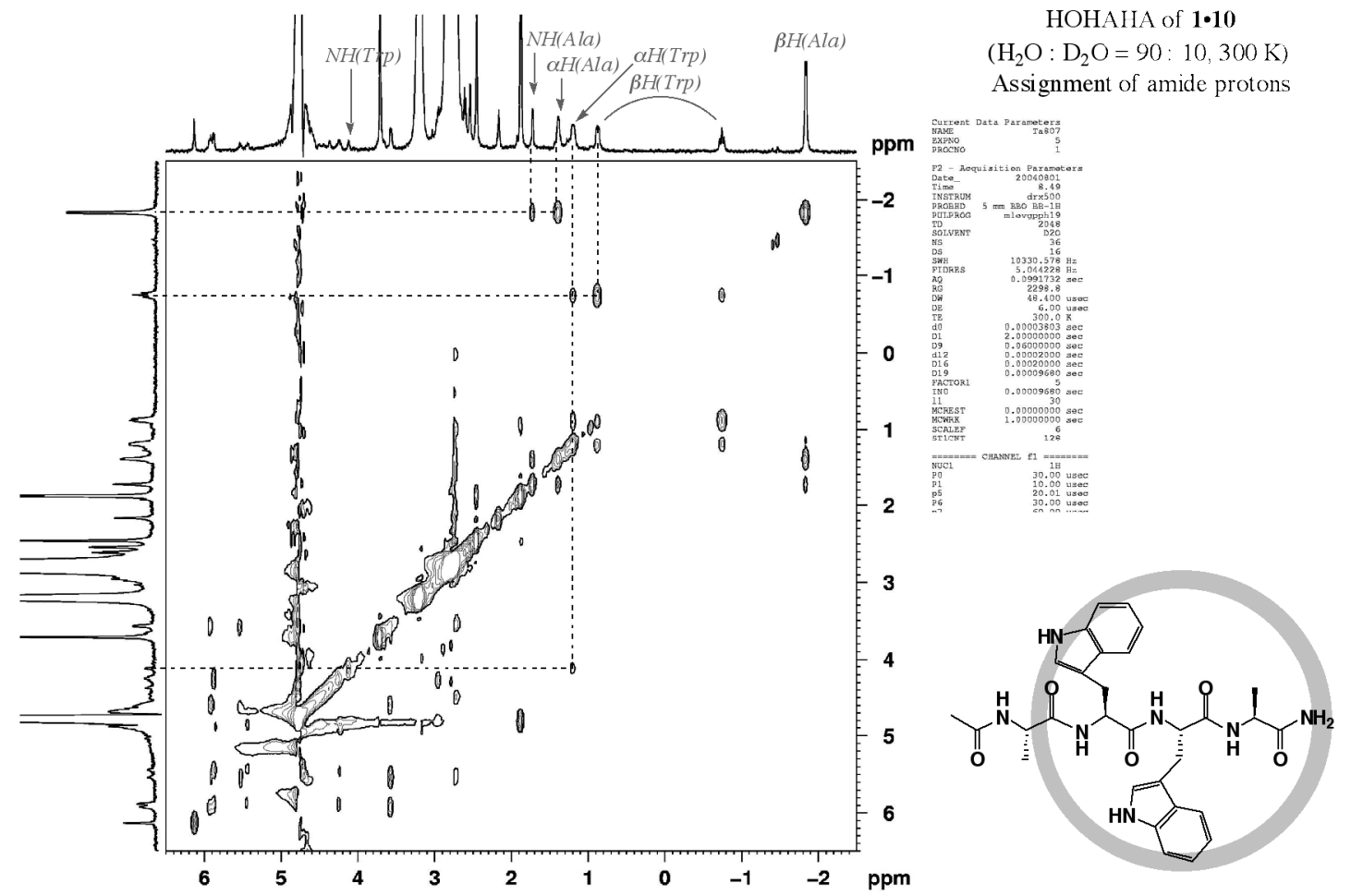

Figure S26.

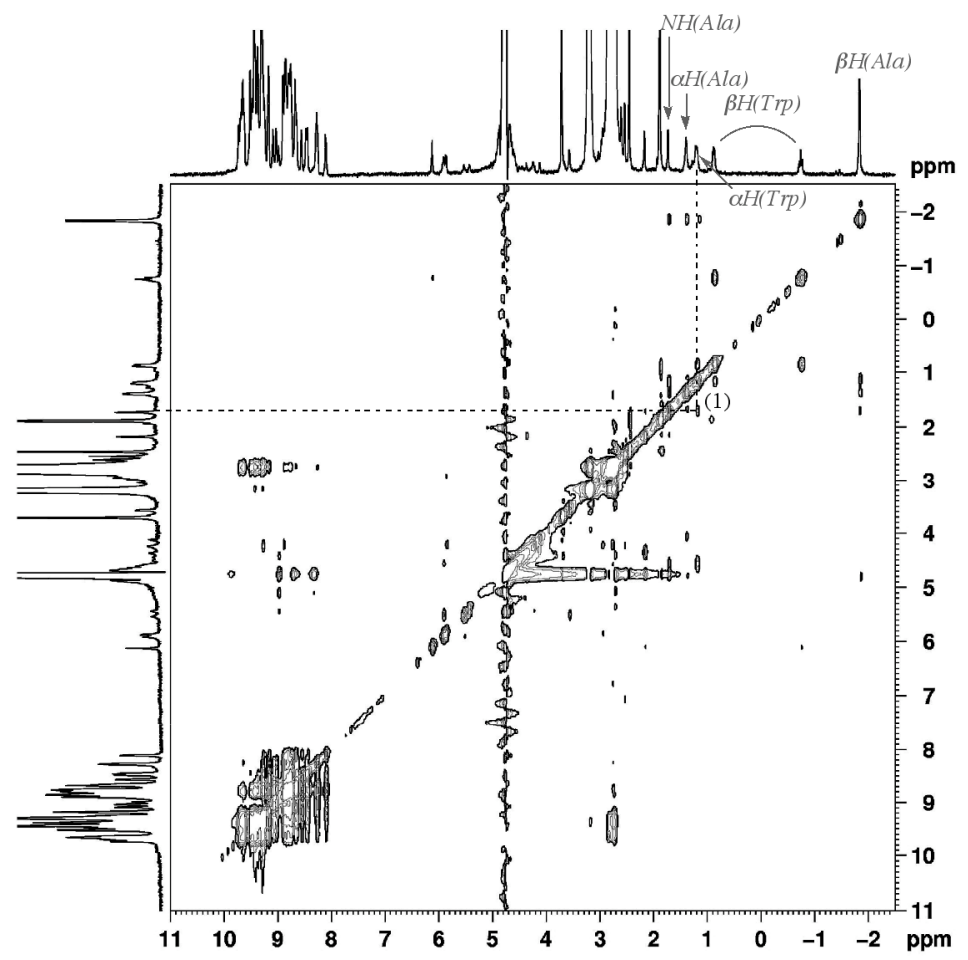

NOESY of $1 \cdot 10$

$\left(\mathrm{H}_{2} \mathrm{O}: \mathrm{D}_{2} \mathrm{O}=90: 10.300 \mathrm{~K}\right)$

Assignment of seque nce

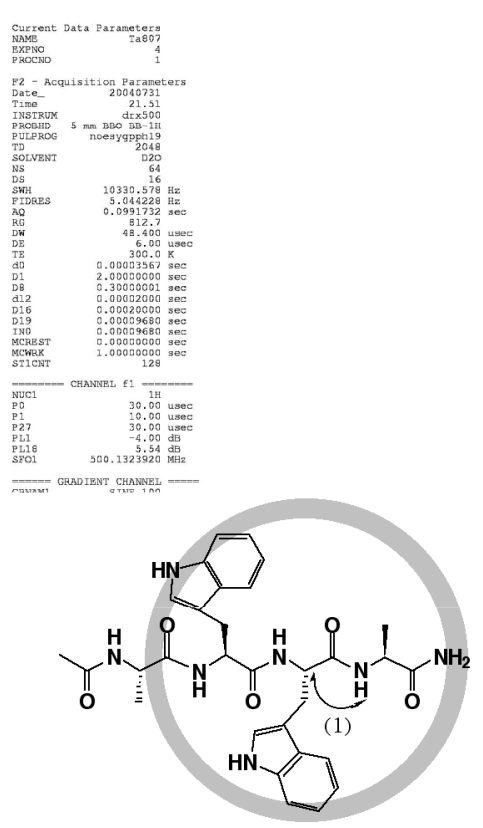




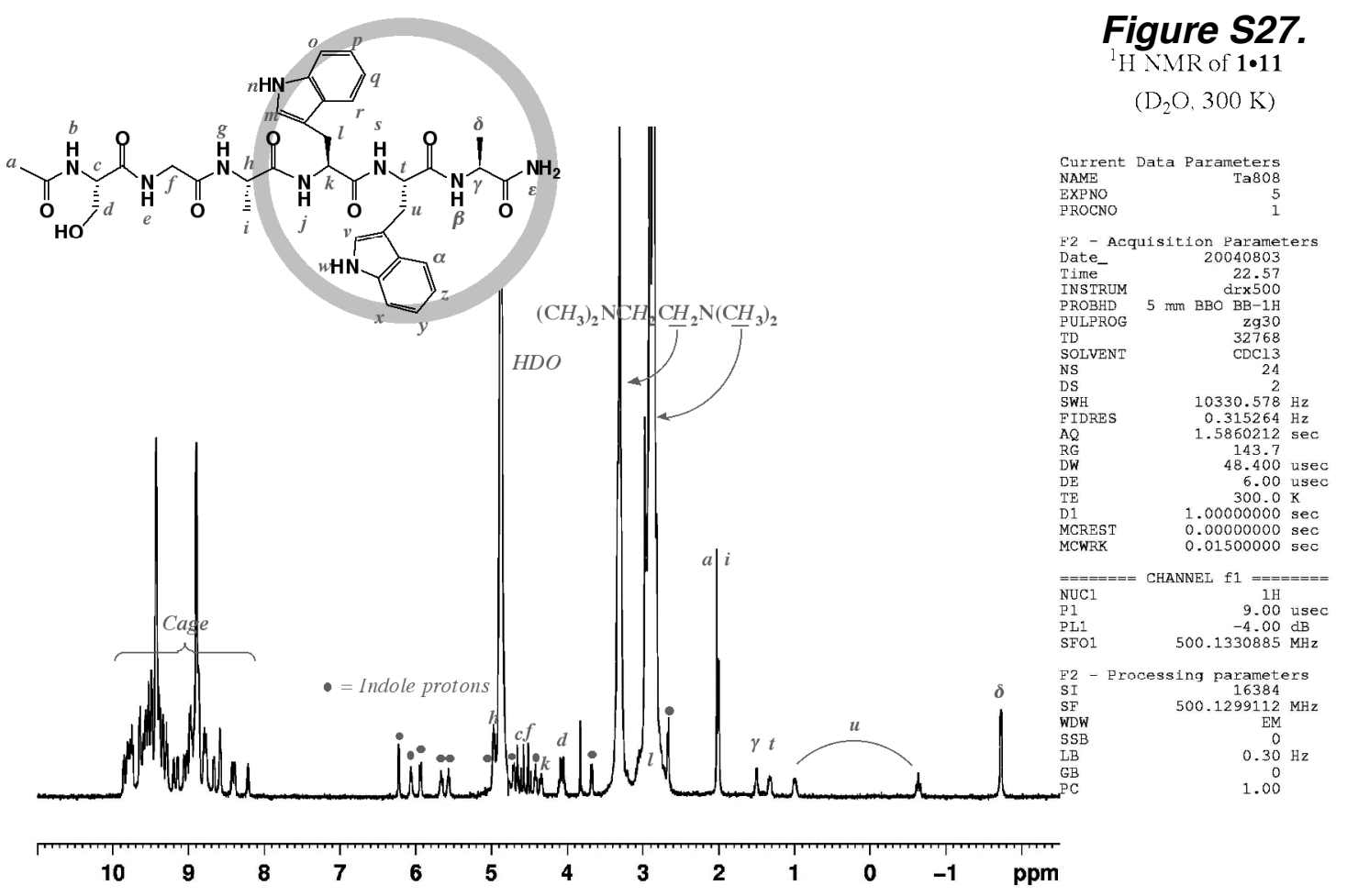

Figure S28.

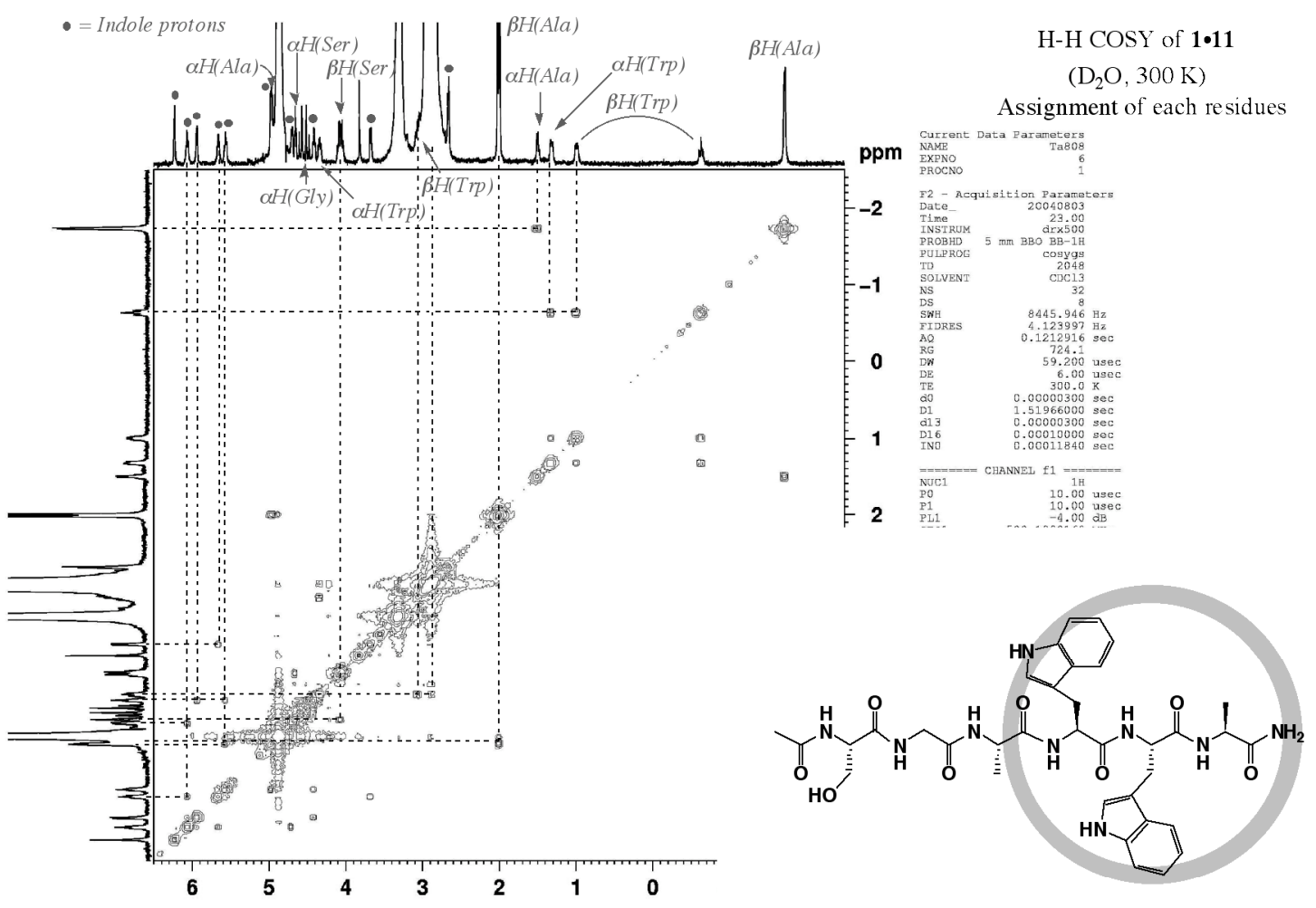


Figure S29.

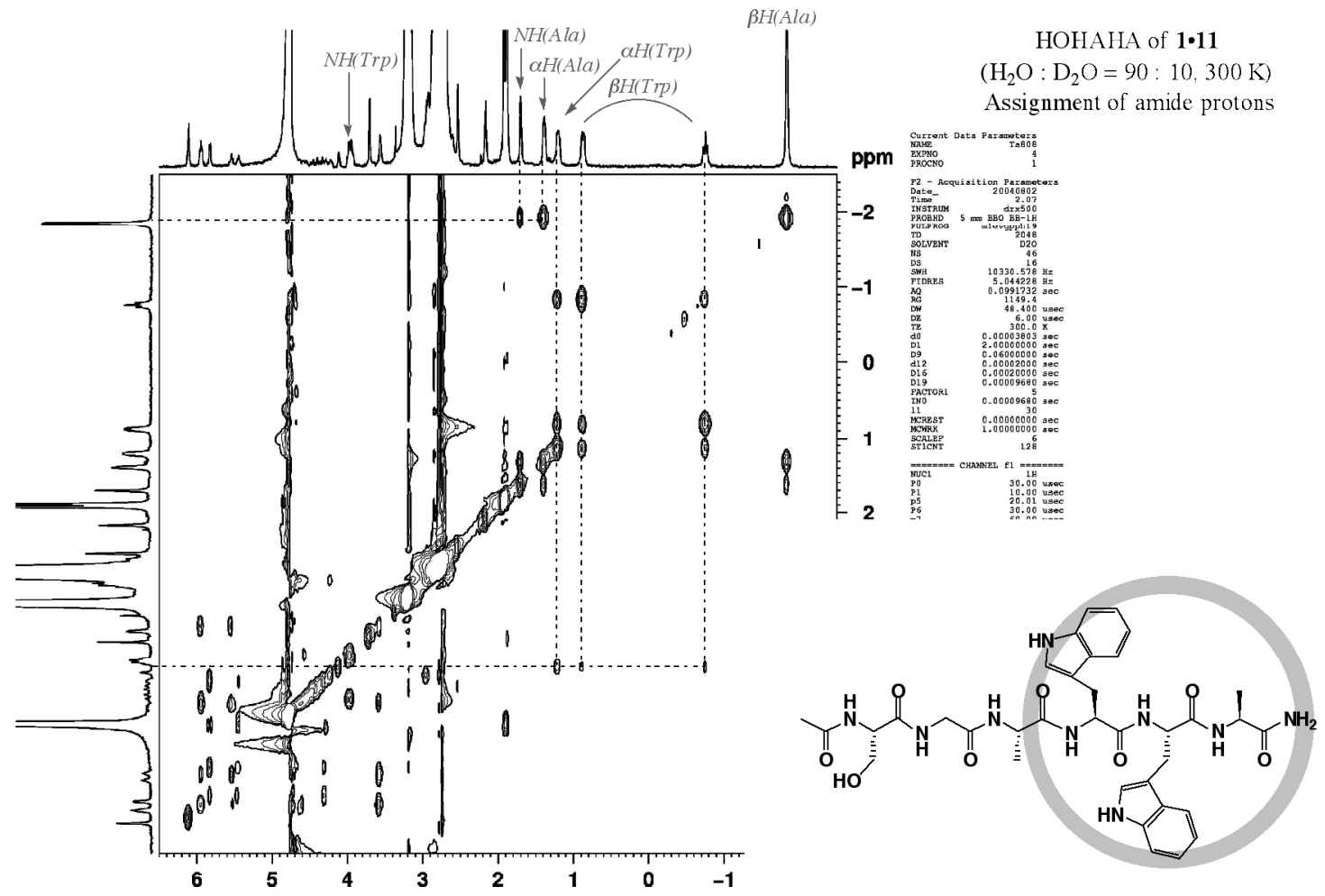

Figure S30.

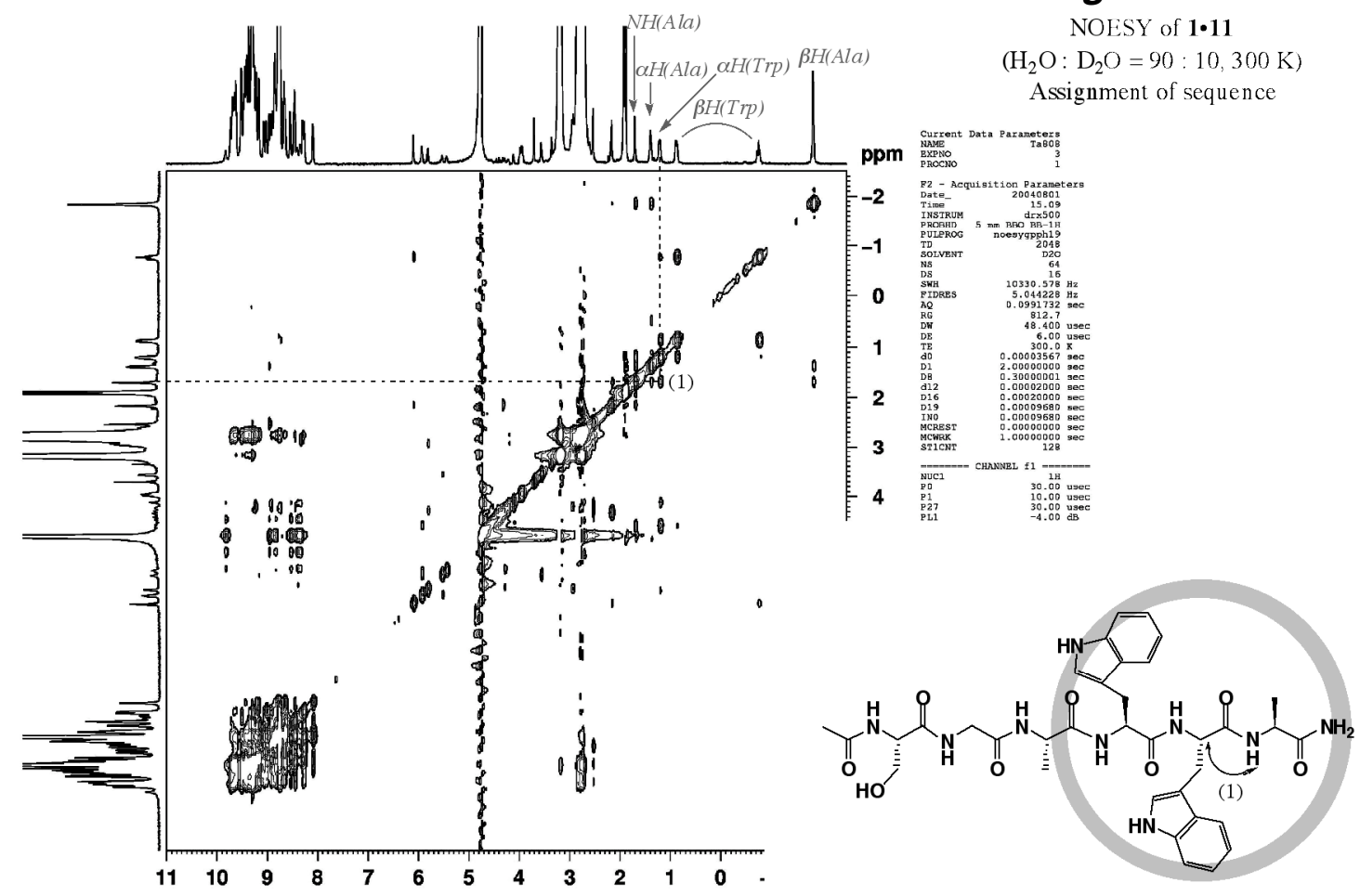




\section{General procedure of $U V$-vis titrations}

A peptide was dissolved in water under sonication and the solution was filtered by a disk-filter to remove trace amount of insoluble impurities. The concentration of peptide was determined by the absorption of Trp and Tyr residues (J. F. Brandts, L. J. Kaplan, Biochemistry 1973, 12, 2011). A $3.0 \mathrm{~mL}$ of peptide solution was placed in a $1 \mathrm{~cm}$ quartz cell. The aqueous solution of cage $1(10 \mathrm{mM})$ was added in portions via microsyringe to the cell. All titrations were carried out at room temperature under slightly acidic condition ( $\mathrm{pH}=4.8-6.0)$. Since cage 1 and the peptide itself have no absorption at $480 \mathrm{~nm}$, the absorption appeared at $480 \mathrm{~nm}$ (or $440 \mathrm{~nm}$ for Tyr-Tyr-Ala) was monitored for the titration. The change in volume due to the addition of a $\mathbf{1}$ was less than $2 \%$. The association constant was calculated by a nonlinear curve-fitting procedure. The Ka values estimated by three titration measurements were averaged.

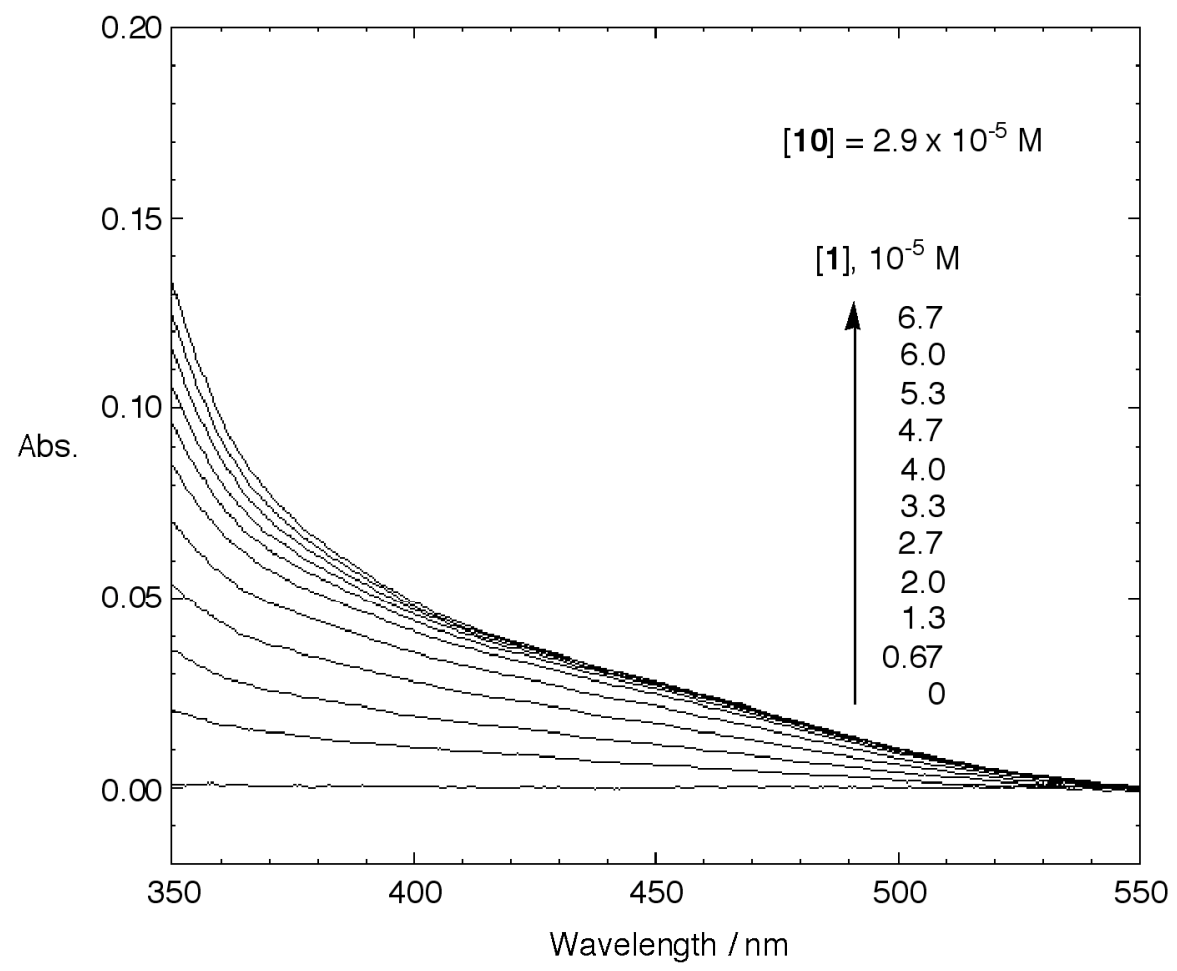

Figure S31. Typical example of UV-vis spectral change. Absorption spectra of the peptide $10\left(2.9 \times 10^{-5} \mathrm{M}\right)$ in the presence of cage 1 . Measurements were performed at room temperature containing the indicated concentrations of $\mathbf{1}$. 


\section{Titrations}
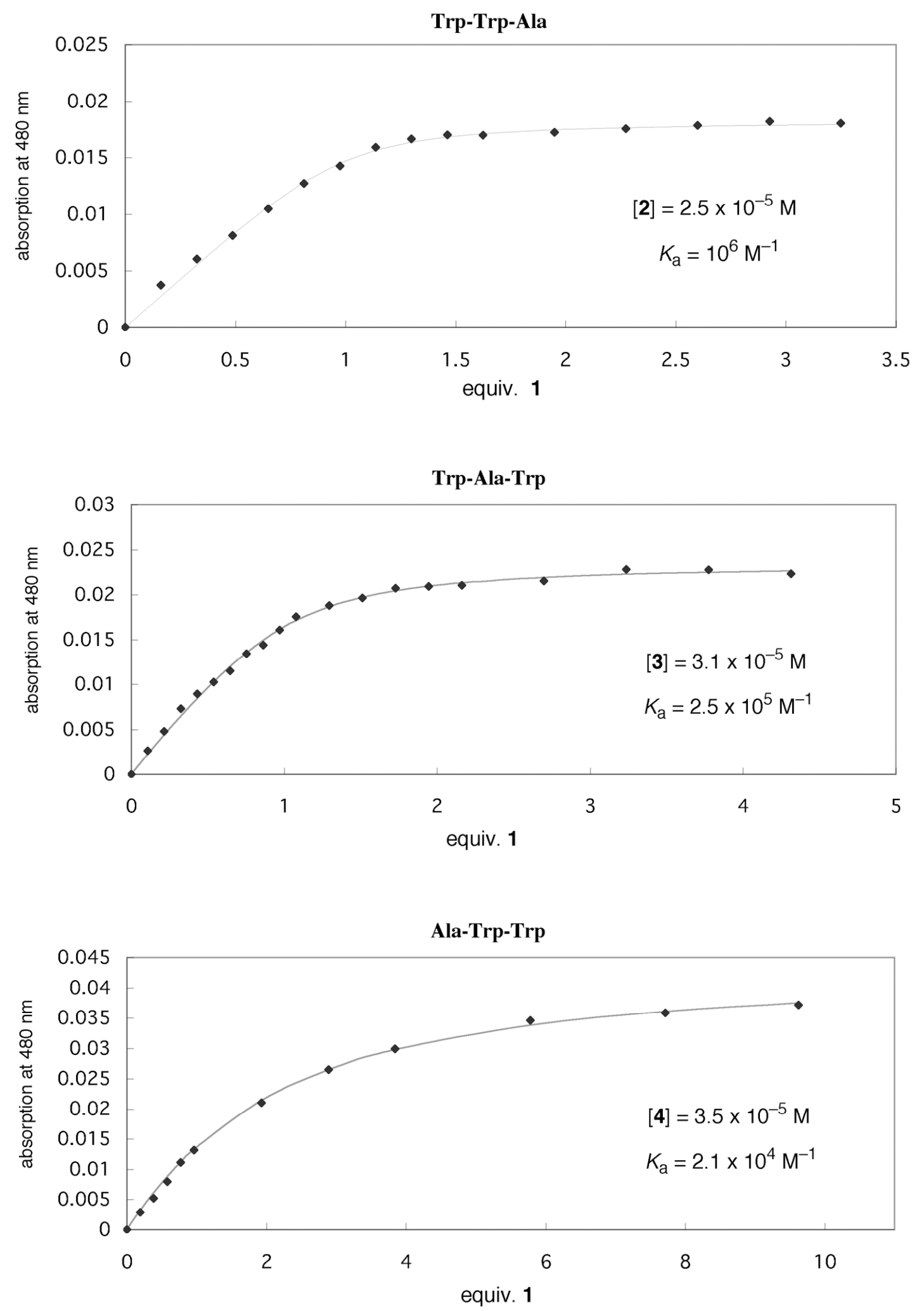

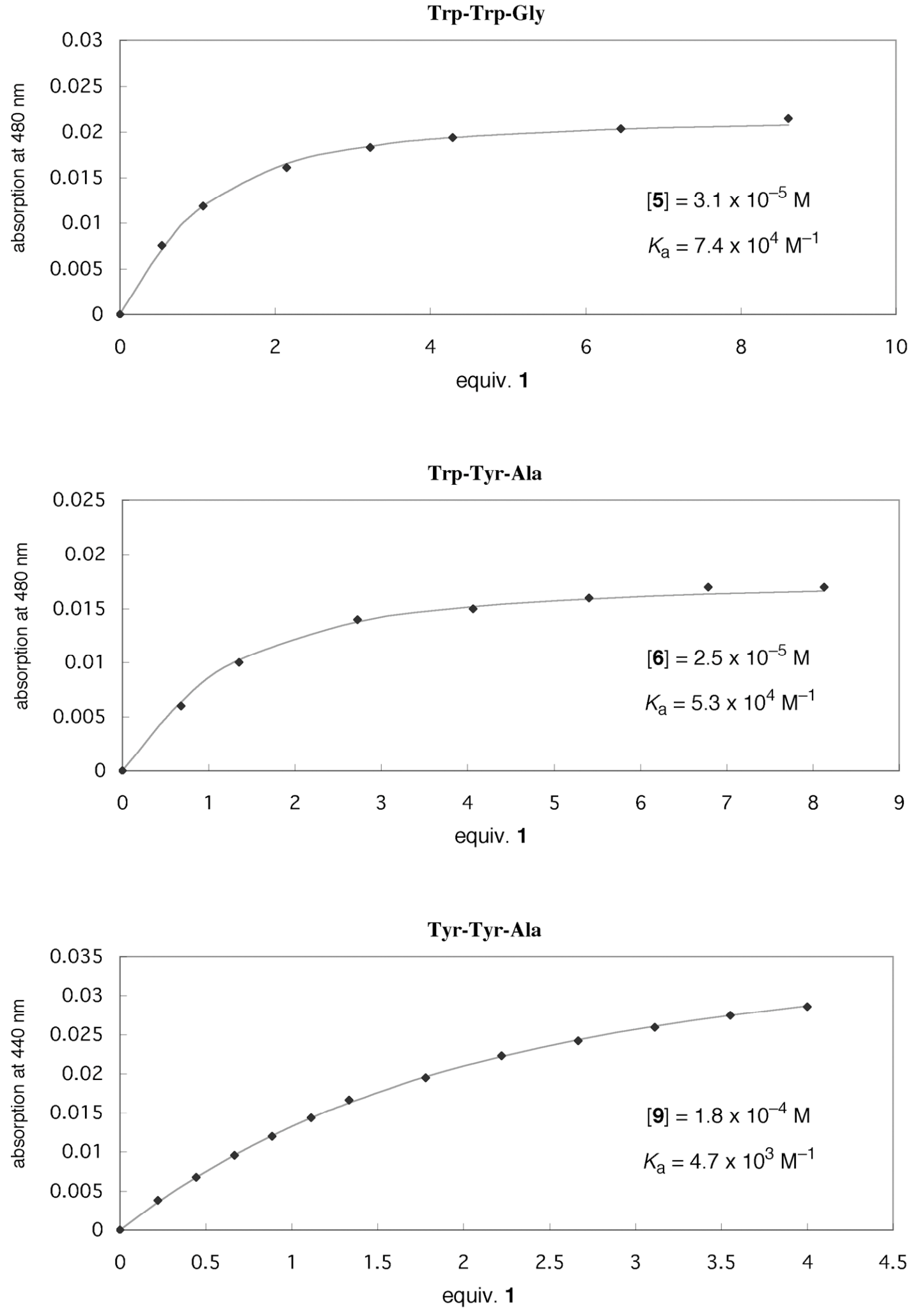

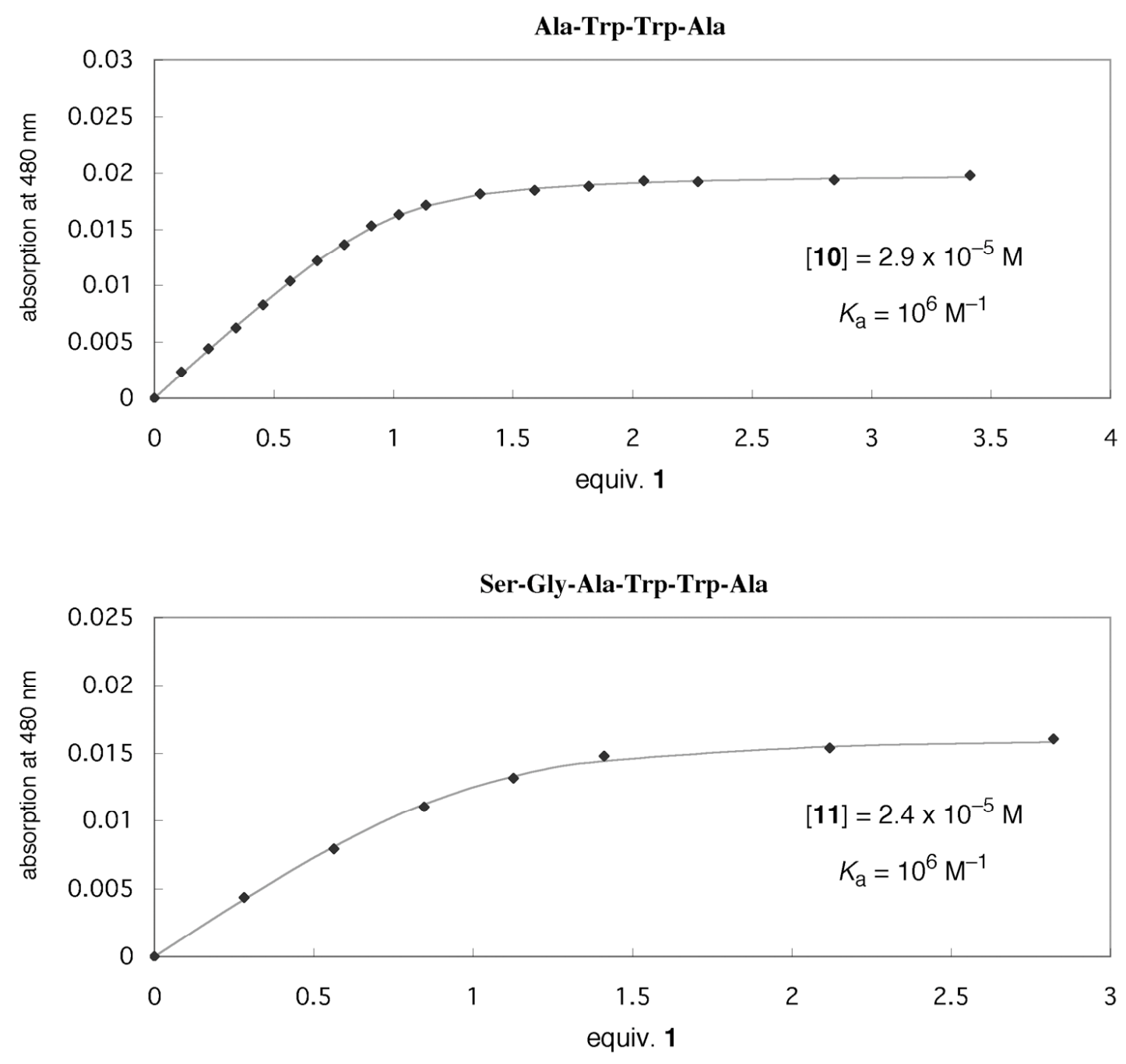

Figure S32. UV-vis titration curves of cage 1 with peptide 2-11 in water. 